\title{
Production and Characterization of a Three-Dimensional Cellular Metal-Filled Ceramic Composite
}

D. Cree and M. Pugh*

Department of Mechanical Engineering, Concordia University

1455 de Maisonneuve Blvd. West

Montreal, Canada H3G 1M8

pugh@encs.concordia.ca

*Corresponding author. 1-514-848-2424 ext. 4190, Fax. 1-514-848-3175, e-mail:

pugh@encs.concordia.ca

\begin{abstract}
Silicon carbide in the form of a foam network was vacuum infiltrated with aluminum alloy A356 to produce a new Interpenetrating Composite material. The foam, once infiltrated with a second phase transforms into a composite where two distinct, continuous, three-dimensional network structures are formed. The advantage of this metal matrix composite is its high strength-toweight ratio for use in lightweight applications such as electronic packaging materials. The electroless nickel coating and vacuum infiltration procedures are developed. Materials characterization of the composite is evaluated by microstructural and compositional analysis, and density, porosity, and nano-indentation measurements. Selected experimental mechanical and thermal property measurements are performed to understand its properties and compare against theoretical models. Results show the final composite to have lower density than conventional electronic base plate packaging materials with low porosity. The composite has an increased Young's modulus and flexural strength to that of the unreinforced alloy and comparable impact toughness to composites with $50-70 \mathrm{vol} \% \mathrm{SiC}$ particles but with only $12 \mathrm{vol} \% \mathrm{SiC}$. The fracture surface of the matrix illustrates conventional fibrous fracture and brittle cleavage whilst the reinforcement struts show signs of layer de-bonding from their $\mathrm{SiC}$ layered structure.
\end{abstract}

Keywords: A356; silicon carbide foam; interpenetrating composite; mechanical and thermal properties 


\section{Introduction}

Interest is growing in the infiltration of a porous ceramic foam structure with a light metal to form a new class of metal matrix composites (MMC) (Zhao et al., 2007). The trend in industry is to reduce the weight of components while maintaining their strength and stiffness. Lightweight products save energy in terms of lower fuel costs and emissions, thus reducing our carbon footprint. For instance, reducing one kilogram of payload can save $\$ 80,000$ over the life of an aircraft, while decreasing one kilogram on a satellite can save $\$ 8$ million dollars for the launch (White et al., 1990). Developing low density composites for use in the transportation industry, specifically in the electronic sector, can provide an advantage over monolithic metals and alloys. Incorporating an interconnected arrangement as reinforcement in a two-phase composite is finding attractive mechanical and thermal property benefits as well as weight savings. This reinforcement network structure performs more efficiently than single isolated solid particles, whiskers or short fibers for the same volume fraction of reinforcement. Example of one potential use for this material is in the base plates for electronic packaging of materials (Rao et al., 2006).

This work focuses on the vacuum infiltration of liquid A356 aluminum alloy into a porous, three-dimensional (3-D), silicon carbide ( $\mathrm{SiC}$ ) foam network structure to produce a MMC. Foams have the advantage of giving a controlled and stable dispersion of reinforcement unlike particulate or fibre reinforcements which can take up various unplanned orientations or can be distributed non-uniformly due to processing or settling for example. Foams can be produced with different porosities, thus the amount of reinforcement can be tailored to a particular engineering application. In the envisaged role for the current material, the $\mathrm{SiC}$ is to provide increased strength and stiffness and to lower the thermal expansion of the composite in order to reduce the thermal stresses on the electronic packaging components, while the aluminum 
phase is preferred for its low-density and high thermal conductivity. Conventional SiC ceramic reinforcements for aluminum MMCs are discontinuous particles, whiskers and short fibers, while continuous reinforcements are fibers. Less familiar is the use of a foam which, once infiltrated with a second phase transforms into a composite where two distinct, continuous, threedimensional network structures are formed to form an interpenetrating phase composite (IPC). Such MMCs with foam reinforcement should have a better strength-to-weight and stiffness-toweight ratios than $\mathrm{SiC}$ particle reinforced composites.

Popular fabrication techniques used for manufacturing aluminum MMCs are based on the infiltration method. Pressure, pressureless and vacuum infiltration are able to produce high yield, near net shape composites. Published experiments have used a wide-range of squeeze casting machine designs to apply pressure to the melt as reported by Chen et al. (2002) whereas other systems use an inert pressurized gas to force the liquid metal into the preform (Xian-qing et al., 2002). Mechanical assistance uses pressures of approximately 65-100 MPa while inert pressurized gas systems use lower pressures, 2-35 MPa. Pressureless infiltration, also known as capillary-driven infiltration is carried out by immersing the ceramic into a molten aluminum alloy bath, at atmospheric pressure (Yang and Xi, 1995). Vacuum infiltration, carried out just below atmospheric pressure was studied by Chung and Lin (1996), and employed in this work for its simplicity, feasibility and low applied pressure which would minimize possible damage to the $\mathrm{SiC}$ foam.

The new $\mathrm{A} 356 / \mathrm{SiC}$ foam composite material described herein has potential application as a heat-sink baseplate material in the electronic packaging industry. The purpose of this study was to develop an aluminum melt vacuum infiltration procedure for the $\mathrm{SiC}$ foam with or without a nickel coating followed by a materials characterization. In the following article, the composite 
microstructure is evaluated using scanning electron microscopy (SEM), phase identification and contamination from the high temperature cement used for bonding the $\mathrm{SiC}$ foam to the quartz tube are verified using X-ray diffraction (XRD), while density and porosity are measured using Archimedes's principle. In addition, the experimental Young's modulus, bend strength and impact toughness behavior will be reported for this novel $\mathrm{A} 356 / \mathrm{SiC}$ foam composite as well as the experimental specific heat capacity, thermal conductivity and coefficient of thermal expansion (CTE) will also be assessed. As a first approximation, the Rule of Mixtures (ROM) theoretical model for predicting Young's modulus, thermal conductivity, specific heat capacity and CTE of two phase composites will be compared against the experimental results.

\section{Experimental Procedure}

\subsection{Materials}

The aluminum/silicon carbide $(\mathrm{Al} / \mathrm{SiC})$ foam infiltration procedure, shown in Figure 1, is carried out with or without nickel coating in order to verify if a 2 wt $\%$ nickel coating affects the wetting behavior of the aluminum alloy on the $\mathrm{SiC}$ and influences the mechanical and thermal properties. It has been reported that the amount of nickel present in the aluminum has a significant impact on the stiffness of the composite and that adding $2 \mathrm{wt} \%$ nickel into pure aluminum increases the strength of the base metal but also reduces the ductility (Hatch, 1984).

The reinforcement is commercially available $\mathrm{SiC}$ Ultrafoam $^{\mathrm{TM}} 100$ pores per inch (PPI), from Ultramet. SiC foam samples are cut to a rectangular shape of $12.5 \mathrm{~mm}$ x $12.5 \mathrm{~mm}$ crosssection, with lengths differing depending on experimental test required. Commercial A356 aluminum alloy (Alcan Inc.) was used as the matrix. This aluminum-silicon (7 wt $\%$ ) alloy is a sand casting alloy used for its low melting point, good flow and wettability characteristics as 
well as to reduce the possibility of forming aluminum carbide at the aluminum/silicon carbide interface. The elemental composition of the A356 aluminum alloy is listed in Table 1.

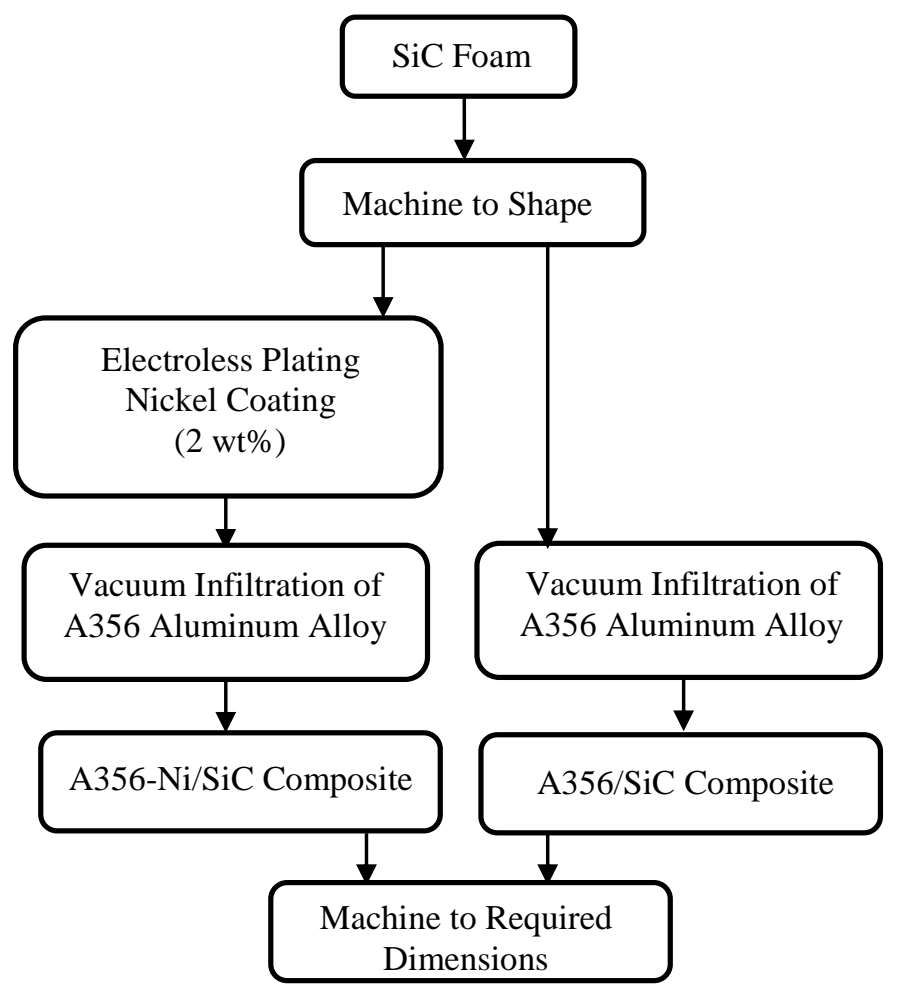

Figure 1. Manufacturing procedure for the A356/SiC foam composite.

Table 1. Elemental composition of the A356 aluminum alloy, wt $\%$.

\begin{tabular}{|c|c|c|c|c|c|c|c|c|c|}
\hline $\mathrm{Al}$ & $\mathrm{Si}$ & $\mathrm{Fe}$ & $\mathrm{Cu}$ & $\mathrm{Mn}$ & $\mathrm{Mg}$ & $\mathrm{Ni}$ & $\mathrm{Zn}$ & $\mathrm{Ti}$ & $\mathrm{Pb}$ \\
\hline 92.262 & 7.10 & 0.10 & 0.006 & 0.01 & 0.38 & 0.003 & 0.008 & 0.13 & 0.001 \\
\hline
\end{tabular}

\subsection{SiC foam pretreatment and coating}

Electroless nickel coating requires a two step process. The SiC foam passes through an initial surface pretreatment preparation where the substrate surface is first cleaned with acetone (15 min) and rinsed 4 times, roughened with nitric acid for 15 minutes, sensitized in a solution of Tin (II) Chloride anhydrous $\left(\mathrm{SnCl}_{2}\right)$, activated for 20 minutes in a solution containing palladium (Pd) ions and further dried to remove any aqueous solution. Chemical ingredient quantities for the five step pretreatment procedure were modified for a foam specimen measuring 3 grams, from 
the work of Leon and Drew (2000) and exact details of chemicals and concentrations are available in that work. The chemicals and amounts are shown in Table 2. In each step the SiC foam was deposited into the solution, manually agitated with a glass rod and ultrasonicated to remove any air bubbles within the porous structure, followed by rinsing with distilled water and drying at $90^{\circ} \mathrm{C}$ for $4 \mathrm{hr}$.

Table 2. Composition of pretreatment solutions.

\begin{tabular}{|ll|}
\hline Sensitization: & \\
Distilled water & $250 \mathrm{ml}$ \\
Tin (II) chloride anhydrous $\left(\mathrm{SnCl}_{2}\right)$ & $1 \mathrm{~g}$ \\
Hydrochloric acid $(\mathrm{HCl})$ & $4 \mathrm{ml}$ \\
\hline Activation: & \\
Distilled water & $250 \mathrm{ml}$ \\
Palladium (II) chloride $\left(\mathrm{PdCl}_{2}\right)$ & $0.025 \mathrm{~g}$ \\
Hydrochloric acid $(\mathrm{HCl})$ & $0.25 \mathrm{ml}$ \\
\hline
\end{tabular}

Following the $\mathrm{SiC}$ foam surface pretreatment, the samples were electroless nickel coated in a solution of Nickel (II) chloride in distilled water with a reducing agent; Borane Dimethylamine complex $\left(\mathrm{BH}_{3} \mathrm{NH}\left(\mathrm{CH}_{3}\right)_{2}\right)$, and a complexing agent; Sodium Acetate, anhydrous $\left(\mathrm{NaOOCCH}_{3}\right)$. The concentration of Borane Dimethylamine was reduced from $0.07 \mathrm{M}$ to $0.04 \mathrm{M}$ to reduce the nickel deposition rate to give a $2 \mathrm{wt} \%$ nickel plating on the foam in a 15 second immersion in the bath as shown in Figure 2. The bath was maintained at $70^{\circ} \mathrm{C}$ and $\mathrm{pH}$ of 7.0. After the pre-determined soaking time, samples were removed from the nickel solution, rinsed with distilled water and dried at $50^{\circ} \mathrm{C}$, in an argon atmosphere for $12 \mathrm{hr}$. The samples were kept in a desiccator until infiltrated with aluminum, to prevent oxidizing the nickel.

\subsection{Infiltration procedure}

A schematic of the vacuum infiltration apparatus is shown in Figure 3. Quartz tubes measuring $17 \mathrm{~mm}$ ID x $19 \mathrm{~mm}$ OD were cut into $21 \mathrm{~cm}$ lengths. The $\mathrm{SiC}$ foam preforms were wrapped with 


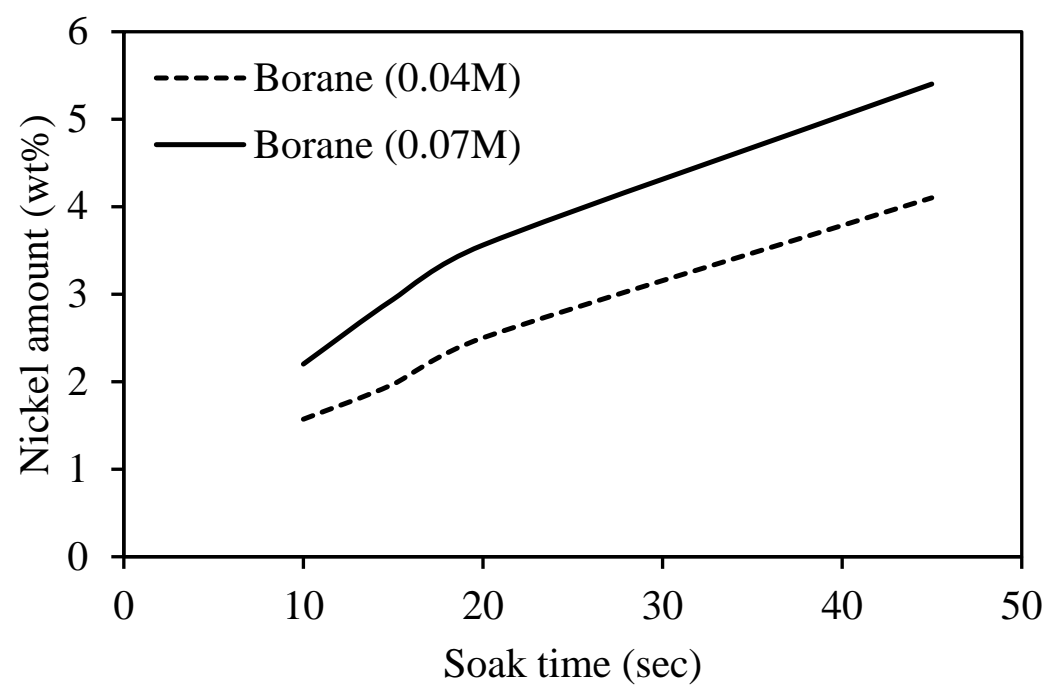

Figure 2. Amount of nickel content in the $\mathrm{SiC}$ foam.

aluminum foil prior to inserting and cementing them into the quartz tube to prevent the high temperature cement from entering into the porous structure. Alumina fiber, was used as a sealant around the square sample as well as employed as a melt flow retardant above the sample. The high temperature cement had a twofold use; (i) bind/solidify the preform to the quartz tube and (ii) act as a sealant between the square preform and cylindrical quartz tube. To prevent the alumina fibers from entering the vacuum system, a steel holding rod with a spiral at the end of approximately the same ID was placed above the sample. The aluminum was melted in a silicon carbide crucible at $775^{\circ} \mathrm{C}$ and the infiltration procedure employed is summarized below.

As described in Figure 4, the oxide layer is skimmed from the top of the melt using a stainless steel spatula. A low vacuum is applied using the needle valve and the sample is submerged approximately $3 \mathrm{~mm}$ into the melt and held for 5 minutes followed by $10 \mathrm{~mm}$ further immersion with 5 minutes holding-time and so on until the sample is fully immersed. Every time the melt flow reaches the top of the specimen, into the alumina fibre, the vacuum is shut off for 10 seconds then turned back on. Once the entire sample is immersed, the maximum vacuum is 


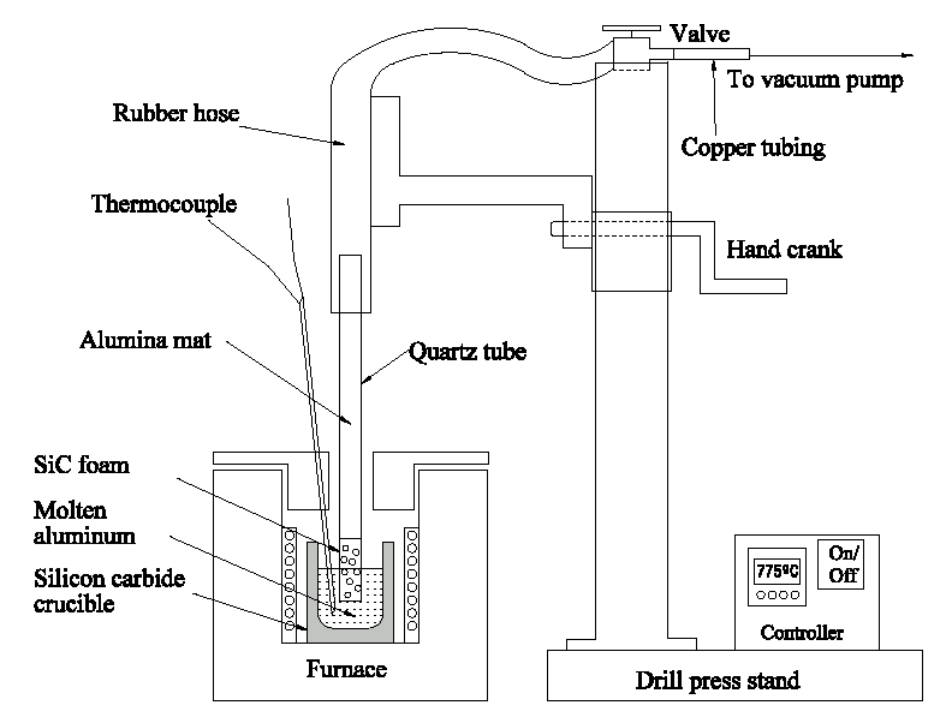

Figure 3. Schematic CAD diagram of the vacuum infiltration apparatus.

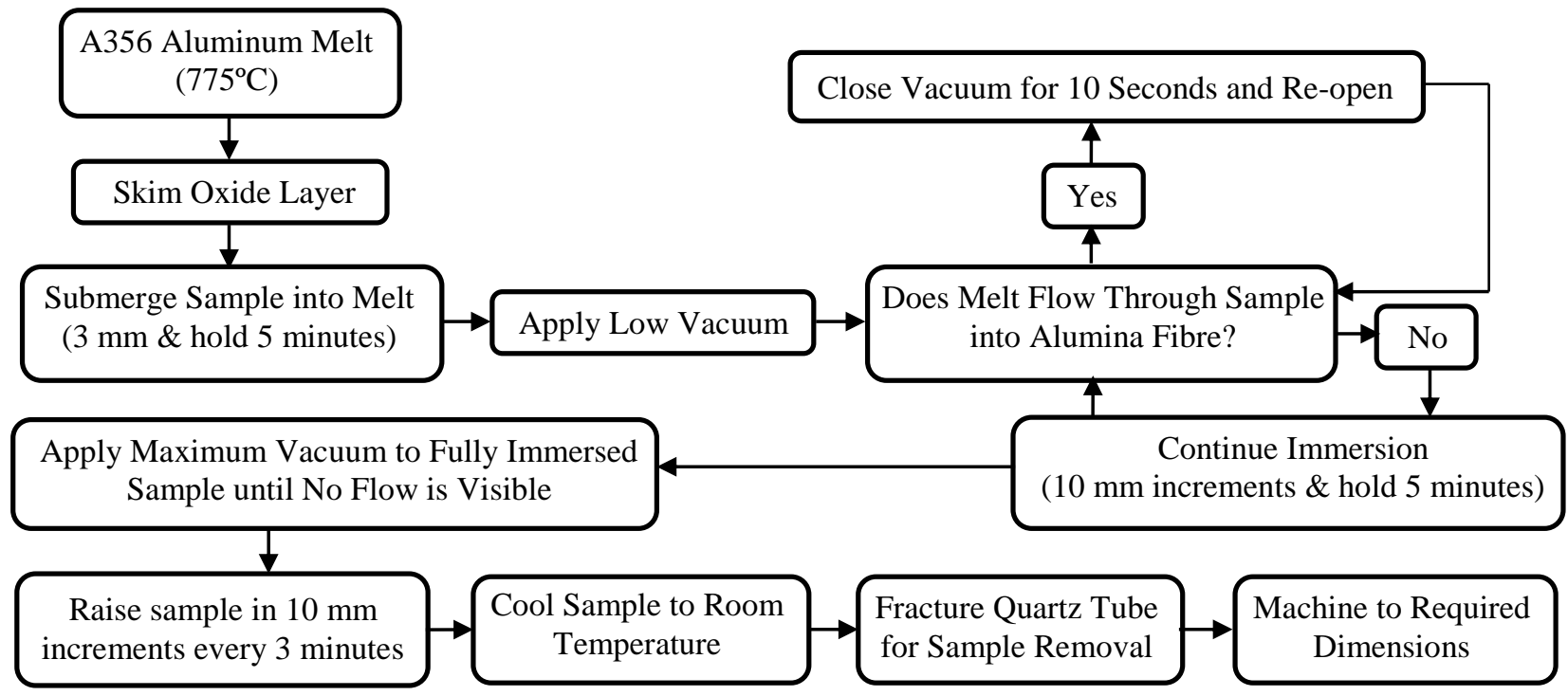

Figure 4. Flow chart depicting the experimental steps involved in the infiltration procedure.

applied until no flow is visible. To mitigate solidification shrinkage, the sample is removed from the melt slowly, raising the sample $10 \mathrm{~mm}$ every 3 minutes until entire sample is out of melt.

Following infiltration, the composite samples were removed from the melt and cooled to room temperature. The quartz tubes were broken to remove the infiltrated samples. All samples were machined using polycrystalline diamond (PCD) milling inserts. Cutting parameters were; 
cutting speed of $242 \mathrm{~m} / \mathrm{min}(800 \mathrm{SFM})$, feedrate of $0.1016 \mathrm{~mm} /$ tooth $(0.004$ inch per tooth) and a depth of cut $0.5-1 \mathrm{~mm}(0.02-0.04$ inch $)$.

\subsection{Characterization}

The morphology of the as-received $\mathrm{SiC}$ foam was evaluated using a scanning electron microscope. Polishing of the A356/SiC foam composite was performed on a JEOL Cross Section Polisher. The sample was imaged using Secondary Electron Imaging (SEI) and backscatter Electron Composition (BEC) detectors.

Different elemental compositions were identified using Energy Dispersive Spectroscopy (EDS). X-Ray Diffraction Spectroscopy (PANalytical Inc) with $\mathrm{Cu}-\mathrm{K} \alpha$ radiation produced at 35 $\mathrm{kV}$ and $20 \mathrm{~mA}$ was used to identify possible intermetallic brittle phase formation at the aluminum/SiC interface as well as contamination in the melt. For example, silica $\left(\mathrm{SiO}_{2}\right)$ contained in the quartz tube can dissolve in the aluminum melt to produce free silicon and alumina. XRD was performed on the as-received A356 aluminum alloy and SiC foam, as well as the high temperature cement, and the melt in the crucible by first turning the samples into powder using a clean metal file. In addition, XRD was performed on the A356/SiC with 0 wt $\%$ and $2 \mathrm{wt} \%$ nickel composites in order to determine if significant quantities of intermetallics were formed.

The water absorption method based on Archimedes's principle (ASTM C 20-00, 2000), Equation 1, was used for determining the open porosity of three foam samples and averaged. The open porosity $\left(\mathrm{P}_{\mathrm{open}}\right)$ is determined from the ratio of the open pore volume $(\mathrm{W}-\mathrm{D})$ to the exterior volume (W-S), where, W, D and S are the saturated weight, dry weight and suspended weight, respectively. The total porosity $\left(\mathrm{P}_{\text {total }}\right)$ was calculated based on the relative density of the composite, Equation 2. The closed porosity was calculated by the difference between the total 
and open porosity. A theoretical density $\left(\rho_{\text {theo }}\right)$ for the carbon/silicon carbide $(\mathrm{C} / \mathrm{SiC})$ strut was estimated using the ROM for a two phase strut as given by Equation 3, where $\rho_{\mathrm{SiC}}, \rho \mathrm{c}, \mathrm{V}_{\mathrm{SiC}}$ and $\mathrm{V}_{\mathrm{c}}$ are the densities and volume fractions of the silicon carbide and carbon respectively.

$\mathrm{P}_{\text {open }}=(\mathrm{W}-\mathrm{D}) /(\mathrm{W}-\mathrm{S}) 100$

$\mathrm{P}_{\text {total }}=(1-$ Relative Density $) 100$

$\rho_{\text {theo }}=\rho_{\text {SiC }} V_{\text {SiC }}+\rho c V_{c}$

The composite bulk density was obtained from the average of three A356/SiC foam composite specimens from mass and volume measurements. The theoretical density of the A356/two phase $\mathrm{SiC} / \mathrm{C}$ composite $\left(\rho_{\text {comp }}\right)$, without nickel and with nickel, was estimated using the ROM, Equation 4 and Equation 5 respectively. Symbols $\rho_{\mathrm{A} 356}, \rho_{\mathrm{Ni}}, \mathrm{V}_{\mathrm{A} 356}$ and $\mathrm{V}_{\mathrm{Ni}}$ are the densities and volume fractions of the A356 aluminum alloy and nickel, respectively.

$$
\begin{aligned}
& \rho_{\text {comp. }}=\rho_{\mathrm{SiC}} \mathrm{V}_{\mathrm{SiC}}+\rho \mathrm{c} \mathrm{V}_{\mathrm{c}}+\rho_{\mathrm{A} 356} \mathrm{~V}_{\mathrm{A} 356} \\
& \rho_{\text {comp }(2 \mathrm{wt} \% \mathrm{Ni})}=\rho_{\mathrm{SiC}} \mathrm{V}_{\mathrm{SiC}}+\rho \mathrm{c} \mathrm{V}_{\mathrm{c}}+\rho_{\mathrm{A} 356} \mathrm{~V}_{\mathrm{A} 356}+\rho_{\mathrm{Ni}} \mathrm{V}_{\mathrm{Ni}}
\end{aligned}
$$

Micro-hardness measurements were performed on the $\mathrm{A} 356 / \mathrm{SiC}$ foam composite in order to verify the hardness and Young's modulus of the composite components. The struts of the foam consist of a carbon interior, enclosed with a multi-layered $\mathrm{SiC}$ structure. To confirm the modulus values of the composite phases (A356, SiC and $\mathrm{C}$ ), hardness and Young's modulus were obtained from a nano-indentation test, (Hysitron Triboscope $\left.{ }^{\circledR}\right)$, equipped with a Berkovich three-sided diamond pyramid indenter with a tip radius of $100 \mathrm{~nm}$. The composite test sample size was approximately $7 \mathrm{~mm}$ in diameter, $4 \mathrm{~mm}$ high and finished to a smooth and parallel surface by grinding with $240,320,400,600,800,1200 \mathrm{SiC}$ grit and polishing using 0.05 micron colloidal silica. Hardness $(\mathrm{H})$ and Young's Modulus of the specimen $\left(\mathrm{E}_{\mathrm{s}}\right)$ were evaluated from the unloading curve of the load-displacement data. The hardness is calculated as the maximum 
indentation force $\left(\mathrm{P}_{\max }\right)$ divided by the projected contact area $(\mathrm{A})$ between the indenter and the specimen.

The modulus of the sample $\left(\mathrm{E}_{\mathrm{s}}\right)$ can be found from Equation 6 .

$\mathrm{E}_{\mathrm{s}}=\left(1-v_{\mathrm{s}}^{2}\right) /\left(1 / \mathrm{Er}-\left(1-v_{\mathrm{i}}^{2}\right) / \mathrm{E}_{\mathrm{i}}\right)$

The poisson's ratio of the material $\left(v_{\mathrm{s}}\right)$ is required for calculation, a value is assumed for all three materials; A356 aluminum alloy, Chemical Vapor Deposition (CVD)-SiC and carbon ( $v_{\mathrm{Al}}=0.33$ (Bindumadhavan et al., 2002), $v_{\mathrm{SiC}}=0.21$ (Jitendra et al., 1991) and $v_{\mathrm{C}}=0.33$ (Li et al., 2003), respectively) The diamond indenter elastic modulus $\left(\mathrm{E}_{\mathrm{i}}\right)$ is $1140 \mathrm{GPa}$ and poisson's ratio $\left(v_{\mathrm{i}}\right)$ is 0.07. The reduced modulus $\left(\mathrm{E}_{\mathrm{r}}\right)$ accounts for the assumed effect that both the specimen and indenter elastically deform during the measured displacement. It is related to the contact area, A and the initial unloading contact stiffness (S), given in Equation 7.

$E_{r}=(\sqrt{ } \pi / 2) /(\mathrm{S} / \sqrt{ } \mathrm{A})$

Generally, the region between $20 \%$ and $95 \%$ of the initial unloading portion of the loaddisplacement curve is used to determine the slope and thus the contact stiffness.

\subsection{Mechanical Properties}

\subsubsection{Compression Test}

Both the as-received $\mathrm{SiC}$ foam ( $\mathrm{SiC}$ Ultrafoam ${ }^{\mathrm{TM}} 100$ pores per inch from Ultramet) and the A356/SiC foam composite were tested in compression. Testing was performed on a Materials Testing Solutions (MTS) system with a $25 \mathrm{kN}$ load cell, at room temperature with a cross-head speed of $0.0015 \mathrm{~mm} / \mathrm{s}$ (equivalent to a strain rate of $0.0001 \mathrm{~s}^{-1}$ ) and no barreling was observed. In order to determine the isotropic behavior of the $\mathrm{SiC}$ foam, three rectangular samples measuring $15 \mathrm{~mm} \times 10 \mathrm{~mm} \times 10 \mathrm{~mm}$ were cut from each direction, $\mathrm{X}, \mathrm{Y}$ and $\mathrm{Z}$ of the as-received $\mathrm{SiC}$ foam. 
The maximum compressive strength was obtained from the position where the linear region ceases and the horizontal plateau begins.

Composite specimens were machined to a square cross-section of $100 \mathrm{~mm}^{2}$ and $15 \mathrm{~mm}$ long, having a length-to-width ratio of 1.5 to avoid failure by buckling. A356/SiC foam specimens were machined from the vacuum infiltrated material. To obtain strain measurements, one strain gauge was installed on the face of each test sample. Low cycle fatigue compression testing was used following the procedure described by Prangnell et al. (1994) to re-distribute the dislocations created due to thermally induced residual stresses from a high density location (matrix/reinforcement interface) to a lower one without damaging the composite material. As

given in Figure 5, the $\mathrm{Al} / \mathrm{SiC}$ foam composites were initially pre-strained to the yield strength of the material, $50 \mathrm{MPa}$. (The yield strength of the $\mathrm{Al} / \mathrm{SiC}$ foam composite was evaluated from conventional compressive stress-strain tests on three samples, prior to pre-straining.) On reaching $50 \mathrm{MPa}$, the stress was reduced to $2 \mathrm{MPa}$, followed by six fatigue cycles (or until an absence of hysteresis is observed) from $2 \mathrm{MPa}$ to $10 \mathrm{MPa}$ at $0.1 \mathrm{~Hz}$. After cycling, it was ramped down to $2 \mathrm{MPa}$ and finally ramped to failure. The Young's modulus was determined from the slope of the linear, low fatigue cycled region. The $\mathrm{Al} / \mathrm{SiC}(0 \mathrm{wt} \% \mathrm{Ni})$ and $\mathrm{Al} / \mathrm{SiC}(2 \mathrm{wt} \% \mathrm{Ni})$ compression composite samples have porosities of $8.55 \pm 0.56 \%$ and $6.91 \pm 0.75 \%$, respectively. Three samples of each porosity level were tested to guarantee reliable results.

\subsubsection{Flexural Test}

Flexural strength testing was carried out at a cross-head speed of $0.5 \mathrm{~mm} / \mathrm{min}$. at room temperature. The four-point bend tests were conducted on the $\mathrm{A} 356 / \mathrm{SiC}$ composites according to (ASTM C 1161-02, 2002). The load and support span loading configurations are $20 \mathrm{~mm}$ and 40 $\mathrm{mm}$, respectively, where the dimensions of the rectangular specimens are machined to $6 \mathrm{~mm} \mathrm{x}$ 
$8 \mathrm{~mm} \mathrm{~mm} \times 50 \mathrm{~mm}$. The theoretical bend strength for the rectangular specimens is given by Equation 8, where $\mathrm{P}$ is the break load, $\mathrm{L}$ is the outer support span, $\mathrm{d}$ is the thickness and $\mathrm{b}$ is width of the specimen.

$\sigma_{4-\mathrm{pt}}=3 \mathrm{PL} / 4 \mathrm{bd}^{2}$

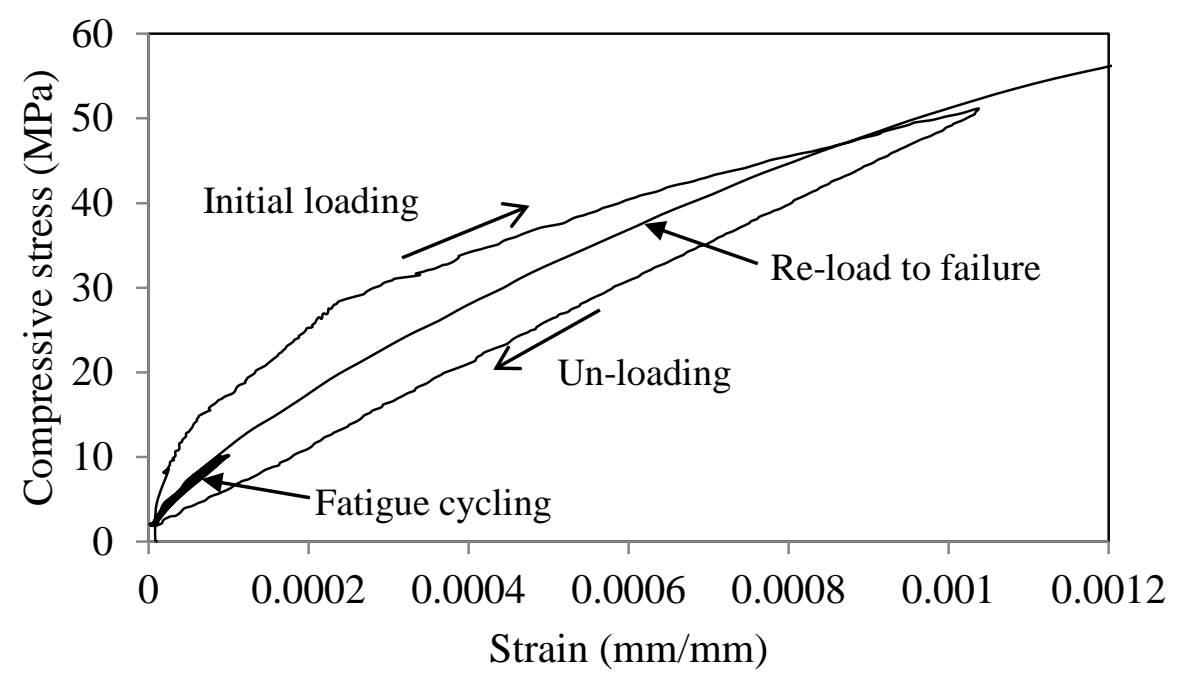

Figure 5. Typical low cycle fatigue compression testing procedure for the $\mathrm{Al} / \mathrm{SiC}$ foam.

\subsubsection{Charpy Impact Test}

The as-cast aluminum and the $\mathrm{A} 356 / \mathrm{SiC}$ foam composite were Charpy tested according to ASTM E 23-02, 2002. Dimensions of the specimens used in this experiment are $10 \mathrm{~mm} \times 10 \mathrm{~mm}$ x $55 \mathrm{~mm}$, machined from the ingot and the as-fabricated composite material. Both v-notched and un-notched configurations were tested in order to determine whether the notch had an effect on the new composite material. Notched samples had a $45^{\circ}$ v-notch, $2 \mathrm{~mm}$ deep, with a $0.25 \mathrm{~mm}$ root radius. Tests were performed on a Charpy impact tester (SI-1B SATEC Systems), at room temperature, on three samples for each configuration and the results were averaged. The microstructure and fracture surfaces were examined by SEM, (JOEL 840A) equipped with an Energy Dispersive Spectroscopy (EDS) system. 


\subsection{Thermal Properties}

Thermal properties were measured on the A356/SiC foam composites with and without nickel. The thermal diffusivity of the composite was measured by the laser flash method (NETZSCH Model LFA447 Nanoflash) from $25^{\circ} \mathrm{C}$ to $275^{\circ} \mathrm{C}$, in steps of $50^{\circ} \mathrm{C}$. Square specimens measuring $12 \mathrm{~mm} \times 12 \mathrm{~mm} \times 1 \mathrm{~mm}$ were ground to 600 silicon carbide grit. To improve the absorption of flash energy as well as the emission of infrared radiation to the detector, three graphite coatings were applied to the composite samples. The specific heat capacity of the $\mathrm{Al} / \mathrm{SiC}$ composite was measured using a differential scanning calorimeter (DSC) (TA Instruments, model Q10), from 20 ${ }^{\circ} \mathrm{C}$ to $300{ }^{\circ} \mathrm{C}$, in steps of $0.25{ }^{\circ} \mathrm{C}$ with a heating rate of $20{ }^{\circ} \mathrm{C} / \mathrm{min}$. The samples were made into a powder using a clean metal file. The heating profile employed was as follows; equilibrate at 0 ${ }^{\circ} \mathrm{C}$, isothermal for 10 minutes, ramp $20^{\circ} \mathrm{C} / \mathrm{min}$ to $300^{\circ} \mathrm{C}$, equilibrate at $300{ }^{\circ} \mathrm{C}$ and isothermal for 10 minutes. Thermal conductivity is calculated from the measured thermal diffusivity $(\alpha)$, specific heat capacity $\left(C_{p}\right)$ and density $\left(\rho_{\text {comp }}\right)$ using Equation 9:

$\alpha=\mathrm{k} /\left(\rho_{\text {comp }} C_{p}\right)$

The CTE of the composite was measured using a thermo-mechanical analyzer (TMA), (TA Instruments model Q400). The CTE was measured from 30 to $300^{\circ} \mathrm{C}$ with a heating rate of $5^{\circ} \mathrm{C} / \mathrm{min}$. The initial specimen was $11 \mathrm{~mm}$ long and $5 \mathrm{~mm}$ in diameter.

\section{Experimental Results and Discussion}

\subsection{Microstructure}

The microstructure of the as-received $\mathrm{SiC}$ foam is shown in Figure 6. The SiC strut surfaces are not smooth as anticipated, which may contribute in wettability reduction. This can be explained by the air/moisture being trapped below the drop of liquid, the larger the cavities, the more air, resulting in a higher contact angle as reported by Quéré (1995). 


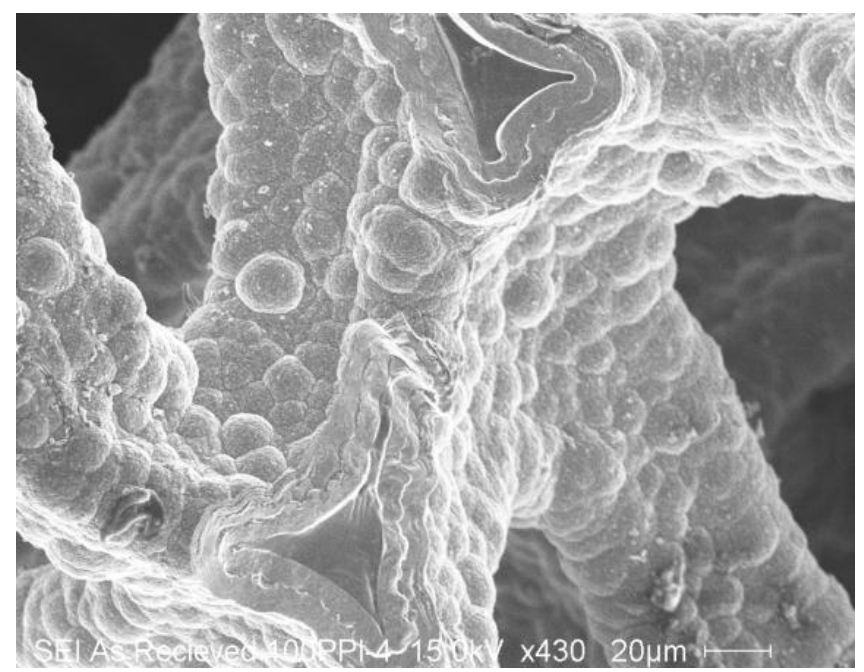

Figure 6. SEM of foam strut surfaces showing a rough profile.

Shown in the cross-section of the A356/SiC foam composite, Figure 7, EDS revealed a twophase strut, a carbon core surrounded by a layer of $\mathrm{SiC}$. At higher magnification, the structure is composed of multi-layers of $\mathrm{SiC}$. Each $\mathrm{SiC}$ layer is separated by a thin dark carbon interface layer. Figure 7 shows the wetting of aluminum onto the $\mathrm{SiC}$ to be reasonable, but with some porosity.

Figure 8 (a) shows an SEM image along with the corresponding X-ray map images (b-e) for element identification. The carbon map is given in (b), the aluminum map in (c), the silicon map in (d) and the nickel map in (e). X-ray mapping was performed on the A356 nickel coated $\mathrm{SiC}$ foam composite in order to determine the location of the nickel. From the nickel map, it appears the nickel has remained on the outer surface of the $\mathrm{SiC}$ foam as it shows up as a definitive line. The nickel coating did not dissolve and segregate around the grain boundaries in the aluminum matrix. The x-ray maps also show the center of the foam to be carbon and the eutectic silicon in the aluminum. Even with a nickel coating, some porosity still exists, possible due to solidification shrinkage. 


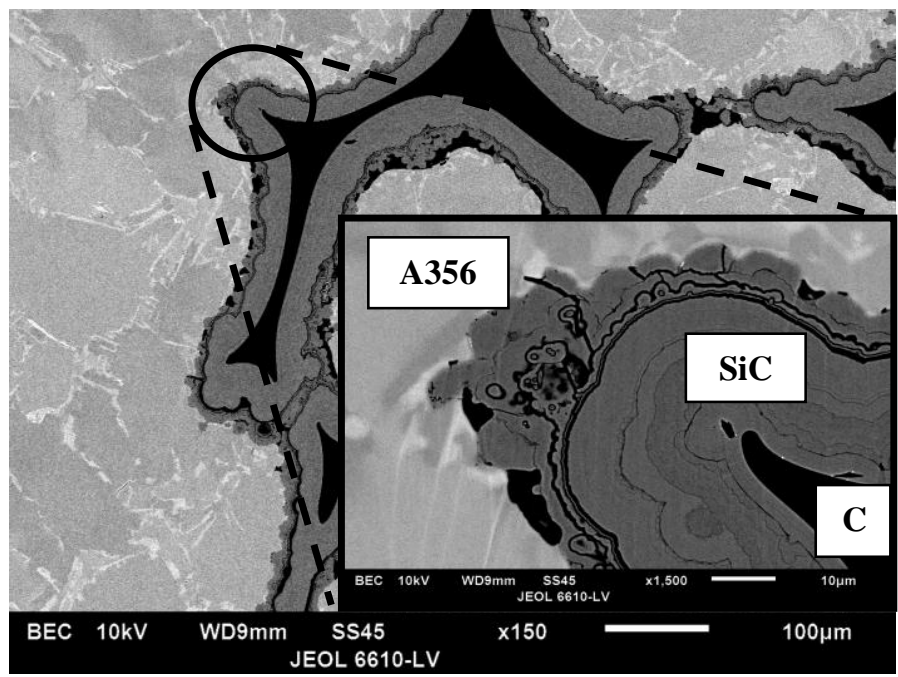

Figure 7. Cross-section SEM image without nickel of the A356/SiC composite alternating layers.

To understand the approximate dimensions and amount of each phase of the SiC foam, optical microscope images were taken of 20 randomly selected cross-sectional shapes of varying geometries at 20x and measured using the Motic Image Plus 2.0 ML software. The strut SiC coating thickness varied between 2.6-13.1 $\mu \mathrm{m}$ for an average thickness of $4.3 \mu \mathrm{m}$. The area ratio of carbon to $\mathrm{SiC}$ of each strut cross-section was measured and an average taken. The SiC coating and carbon center were found to have an average area of $796 \mu \mathrm{m}^{2}$ and $249 \mu \mathrm{m}^{2}$, respectively. The results provide a volume fraction of 0.24 and 0.76 for carbon and $\mathrm{SiC}$, respectively. However, due to strut junctions, there may be more carbon in these areas of the foam. This was verified by oxidizing the carbon from the $\mathrm{SiC} / \mathrm{C}$ as received foam at $700^{\circ} \mathrm{C}$ for one hour in order to determine the mass fractions of the each phase. Prior to oxidation, the C/SiC CVD powder (crushed into powder form) contained $0.574 \mathrm{~g}$, while after oxidation, the powder sample weight was 0.081 g. Cowlard and Lewis (1967) determined the bulk density of carbonized vitreous (glassy) carbon to be $1.47 \mathrm{Mgm}^{-3}$, while the density of a CVD SiC layer grown on a vitreous carbon substrate was measured to be $3.21 \mathrm{Mgm}^{-3}$ after removal of the carbon (Derre, 1995). Employing the appropriate densities and knowing the mass of each constituent, the volume 


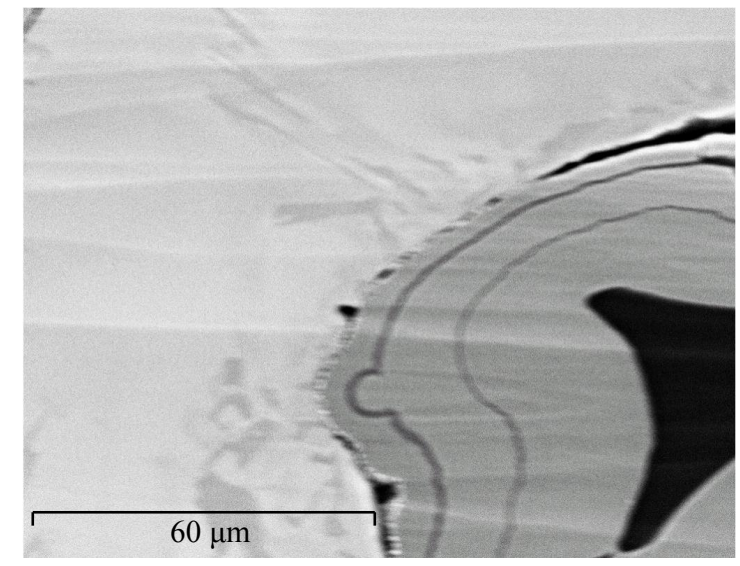

(a)

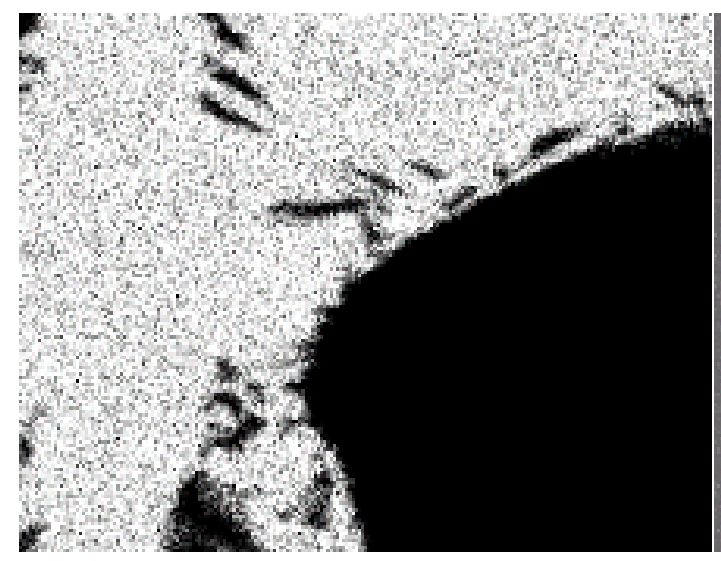

Aluminum Ka1

\section{CarbonKa1_2}

(b)

(c)

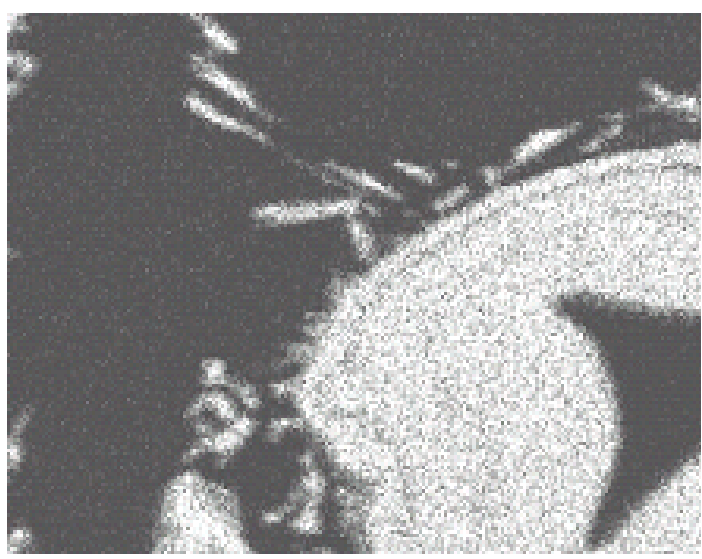

Silicon Ka1

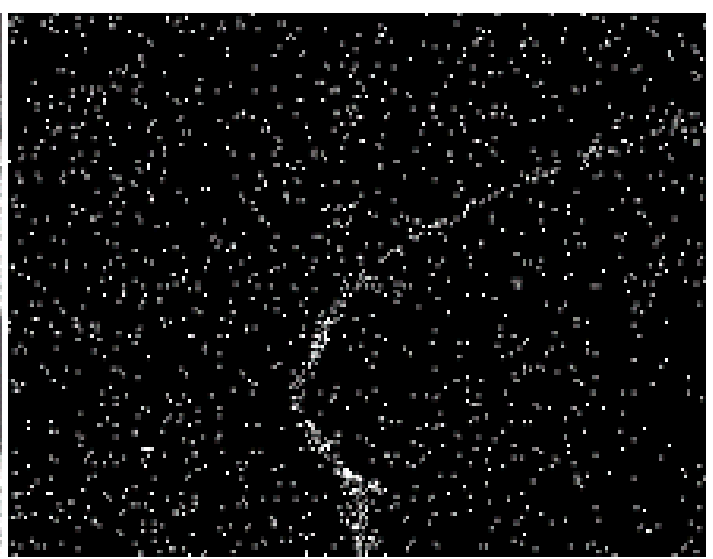

Nickel Ka1

(d)

(e)

Figure 8. SEM image (a) X-ray map images of A356, nickel coated SiC foam composite (b-e). 
fraction of the $\mathrm{SiC}$ and carbon are 0.77 and 0.23 , respectively, after oxidation.

\subsection{Composition}

The XRD pattern of as-received A356 aluminum alloy, oxidized SiC foam, high temperature cement, melt in the crucible after ten infiltrations and the A356/SiC composites with and without nickel are shown in Figure 9. Results for $0 \mathrm{wt} \%$ and $2 \mathrm{wt} \%$ nickel shows an identical XRD diffraction pattern as the $\mathrm{A} 356 / \mathrm{SiC}$ foam composite without nickel, indicating that the amount of nickel present is below the detection limit of the XRD detector. Al-SiC and Al-Ni intermetallics were not detected in the composite samples. According to the Al-Ni phase diagram, it requires more than $40 \mathrm{wt} \%$ of nickel in aluminum to form intermetallic compounds. The most intensive peak in the high temperature cement is not in the composite or in the crucible melt. Therefore no contamination is apparent after ten $\mathrm{SiC}$ foam infiltrations.

\subsection{Density}

The density of the foam and $\mathrm{A} 356 / \mathrm{SiC}$ foam composite was evaluated by different methods as given in Figure 10. The foam bulk density was obtained by geometrical volume and dry mass measurements of three samples giving a value of $0.32 \pm 0.003 \mathrm{Mgm}^{-3}$. The theoretical density for the $\mathrm{C} / \mathrm{SiC}$ strut was estimated using the ROM, Equation 3 for a two phase strut. Employing the theoretical CVD SiC density $\left(\rho_{\mathrm{SiC}}\right)$, vitreous carbon density $\left(\rho_{\mathrm{c}}\right)$ and the volume fractions of carbon $\left(\mathrm{V}_{\mathrm{c}}\right)$ and $\mathrm{SiC}\left(\mathrm{V}_{\mathrm{SiC}}\right)$ from the oxidization test, the strut density is calculated to be 2.82 $\mathrm{Mgm}^{-3}$. The drop in density from pure $\mathrm{SiC}$ is due to the carbon interior of the foam strut. 


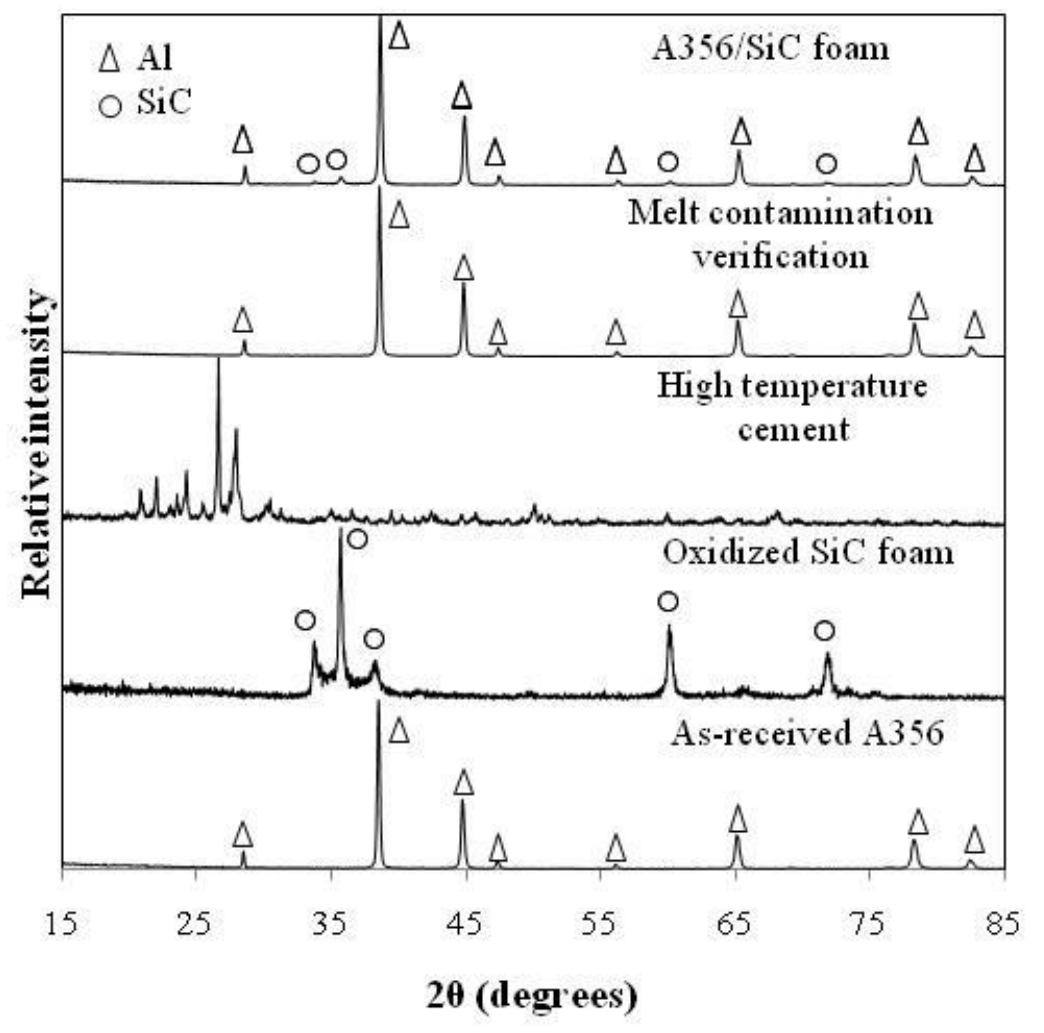

Figure 9. XRD powder pattern of as-received A356 aluminum alloy, oxidized SiC foam, high temperature cement, crucible melt after ten infiltrations and the $\mathrm{A} 356 / \mathrm{SiC}$ composites with and without nickel.

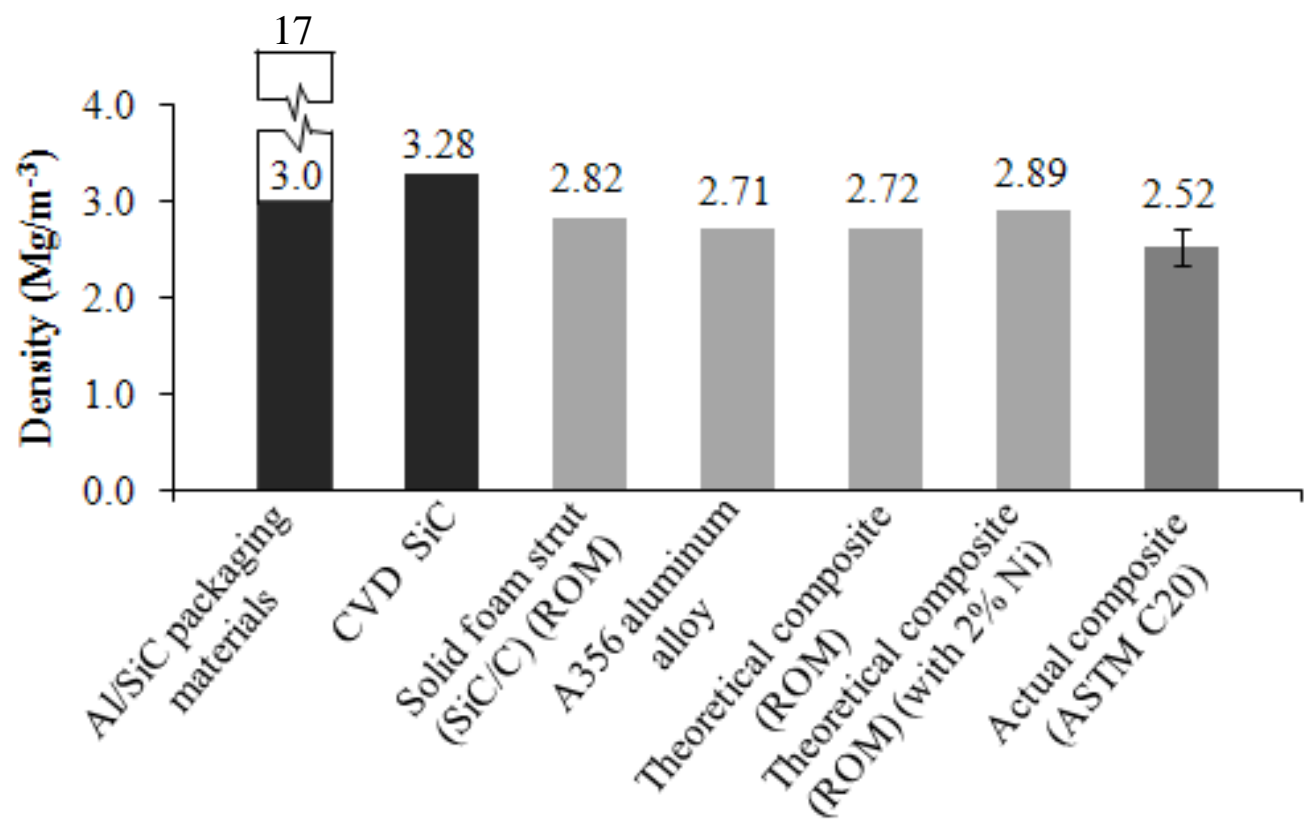

Figure 10. Comparison of various bulk density values. 
The A356/SiC foam composite experimental bulk density and measured by the more accurate Archimedes method was evaluated to be $2.58 \pm 0.13 \mathrm{Mgm}^{-3}$ and $2.52 \pm 0.18 \mathrm{Mgm}^{-3}$, respectively. The density of the $\mathrm{A} 356 / \mathrm{SiC}$ foam composite based on $\mathrm{ROM}$, Equation 4 and knowing the porosity of the foam is $88 \%$ estimates the composite density to be $2.72 \mathrm{Mgm}^{-3}$. From Equation 5, 2\% nickel, increased the density to $2.89 \mathrm{Mgm}^{-3}$. Deviation of the experimental density from the basic assumption is due to porosity. Adding SiC reinforcement to aluminum alloy, leads to an increase in density, thus the volume fraction of SiC should be minimized as much as possible. The advantage of using foam enables low volume fraction reinforcement of $12 \%$ for the 100 PPI SiC foam.

\subsection{Porosity}

The total porosity of the foam was evaluated using Equation 2. Based on the foam bulk density $0.32 \mathrm{Mgm}^{-3}$ and theoretical two-phase $(\mathrm{C} / \mathrm{SiC})$ strut density of $2.82 \mathrm{Mgm}^{-3}$, the calculated total porosity is $88.65 \%$. Archimedes open porosity was measured to be $87.67 \%$, from Equation 1 . Porosity of the $\mathrm{A} 356 / \mathrm{SiC}$ foam composite was evaluated similar to the foam porosity. Assuming the $\mathrm{Al} / \mathrm{SiC}$ foam composite theoretical density of $2.72 \mathrm{Mgm}^{-3}$ (based on the ROM for a solid foam strut density of $2.82 \mathrm{Mgm}^{-3}$ and bulk density of $2.52 \pm 0.18 \mathrm{Mgm}^{-3}$ ), the total porosity of the composite is $7.35 \pm 0.18 \%$. An SEM image showing the porosity in the Al/SiC foam composite is given in Figure 11.

Porosity formation in aluminum can be due to two reasons; hydrogen gas is released from the melt and can also be caused by the inherent solidification shrinkage during cooling. Hydrogen is a product from the reaction of moisture $\left(\mathrm{H}_{2} \mathrm{O}\right)$ in the atmosphere with the aluminum. It can enter the aluminum melt during stirring or pouring, but could also be present from the as-received 
ingot from the foundry. Porosity from hydrogen gas bubbles will form spherical holes in the solidified structure if not removed from the melt using a degassing method (Kaufman, 2004).

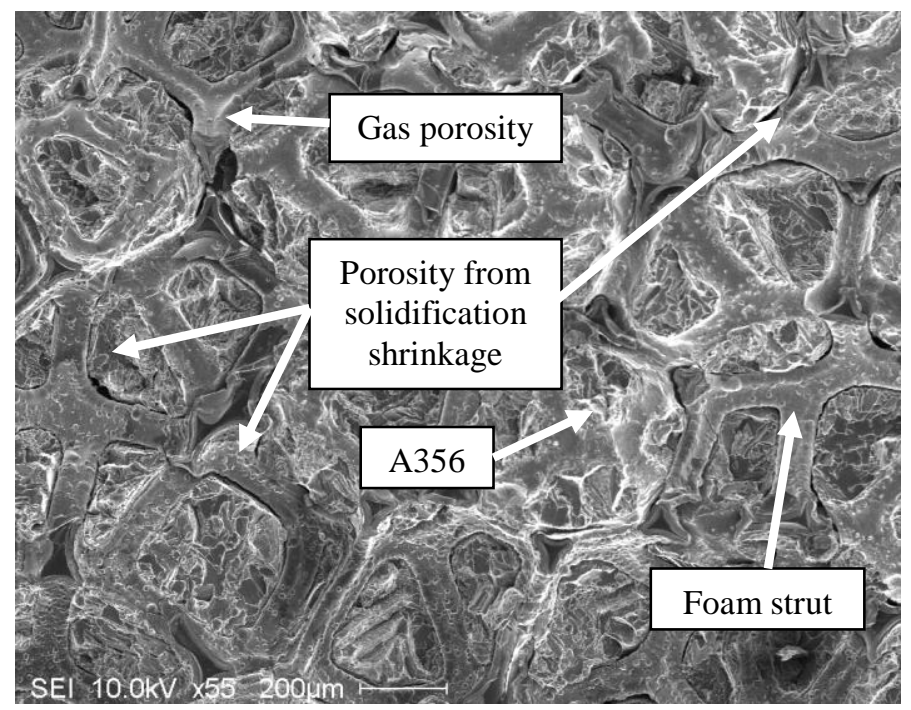

Figure 11. SEM image showing porosity in the $\mathrm{Al} / \mathrm{SiC}$ foam composite.

Solidification shrinkage of aluminum alloy in castings is due to the volume change during the phase transformation from liquid to solid. The solidification shrinkage of pure aluminum is $7 \%$, while for aluminum casting alloys ranges between 5 to $6 \%$ as was observed by Ahson and Gruzleski (1999). Shrinkage can be compensated by feeding molten aluminum into the opencelled preform during solidification. Current electronic $\mathrm{Al} / \mathrm{SiC}$ packaging materials have bulk densities, typically 3-17 $\mathrm{Mgm}^{-3}$ as reported by Occhionero et al. (1999). This composite has a lower bulk density than packaging material of 50-70 vol\% particulate reinforcement as only 12 vol\% reinforcement is used. The density is reduced from $3.0 \mathrm{Mgm}^{-3}$ to $2.52 \mathrm{Mgm}^{-3}$, which has the advantage of decreasing the weight of a packaging component by $16 \%$.

\subsection{Nano-indentation}

The nano-indentation behavior of the A356 aluminum alloy, and the cell wall materials ( $\mathrm{SiC}$ and carbon) are depicted in the load-displacement curves, Figure 12. The carbon being harder then 
the aluminum shows a lower penetration depth for the same applied load, whereas the $\mathrm{SiC}$ is stiffer and harder than the preceding materials and penetrates much less. Three indentation point measurements at constant intervals of $20 \mu \mathrm{m}$ where made on the aluminum matrix as well as the carbon and $\mathrm{SiC}$ cross-sectional regions of the foam strut to obtain an average assessment. All averaged values were accurate as depicted by the relatively low standard deviations given in Table 3. However, the hardness values for the $\mathrm{SiC}$ coating and carbon interior have lower accuracies than the aluminum alloy. This may be attributed to the number of sampling points taken or the polishing procedure employed. As a result of the characteristics of the materials, the softer carbon and aluminum were observed to be removed quicker than the harder SiC. This may have hindered a parallel SiC surface.

Each indentation experiment consisted of three phases as follows; upon surface contact, the indenter is loaded at a constant rate of $200 \mu \mathrm{N} / \mathrm{s}$ to peak load of approximately $924 \mu \mathrm{N}$. The penetration depths of $14 \mathrm{~nm}(\mathrm{SiC}), 16 \mathrm{~nm}(\mathrm{C})$ and $148 \mathrm{~nm}(\mathrm{Al})$ were observed.

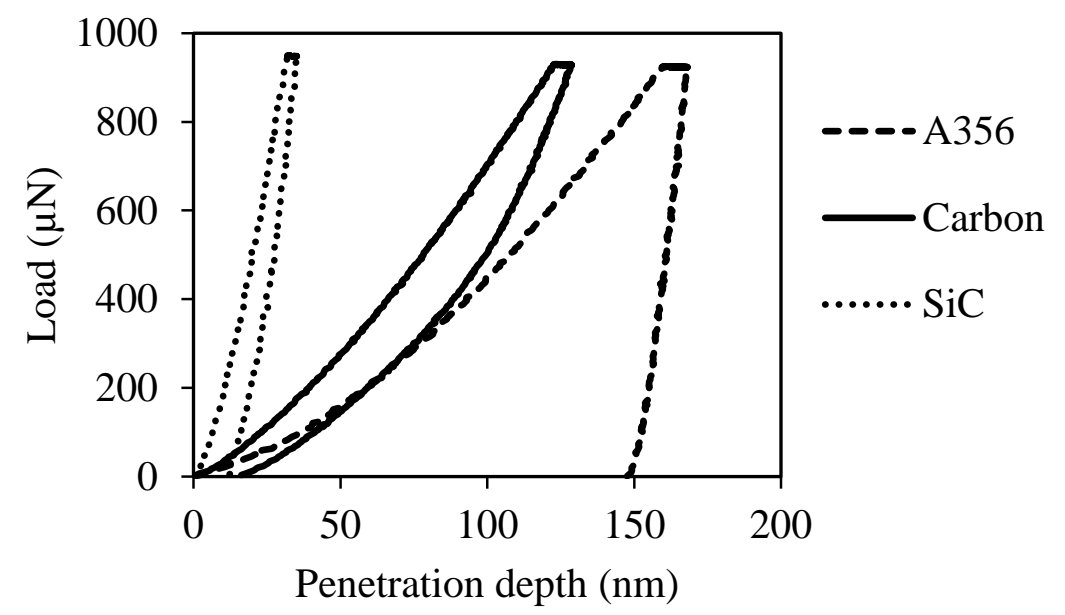

Figure 12. Load-penetration depth curves for the A356/SiC foam composite. 
Table 3. Nanoindentation hardness and Young's modulus results.

\begin{tabular}{|l|c|c|}
\hline Nano-indentation & $\begin{array}{c}\text { Modulus } \\
(\mathrm{GPa})\end{array}$ & $\begin{array}{c}\text { Hardness } \\
(\mathrm{GPa})\end{array}$ \\
\hline A356 matrix & $71 \pm 2.0$ & $1.55 \pm 0.08$ \\
\hline SiC coating & $307 \pm 23.7$ & $57 \pm 8.99$ \\
\hline Carbon interior & $27 \pm 2.1$ & $6 \pm 0.50$ \\
\hline
\end{tabular}

The peak load is held constant for 5 seconds and subsequently unloaded at a rate of $5 \mu \mathrm{N} / \mathrm{s}$. When the peak load is held constant for five seconds the displacement or penetration depth increase. The indenter movement ranges between 5-10 $\mathrm{nm}$ depending on the material being tested, aluminum or silicon carbide. Aluminum will creep more than $\mathrm{SiC}$, but the exact amount of creep will depend on the loading rate, probe geometry, peak force, and the properties of that particular specimen, but it is normal behavior for many materials. The reason for incorporating a hold segment into the load function is to minimize any effects of creep during unload, which is the segment used to calculate hardness and modulus.

\subsection{Mechanical Properties}

\subsubsection{Compression Test}

Figure 13 is a typical compressive stress-strain curve for the SiC ceramic foam. Initially, the load increases linearly until a reduction in slope occurs. The samples begin to crush and damage is observed on the top and bottom of the sample as broken ceramic material. The $\mathrm{X}$ and $\mathrm{Z}$ directions have similar strengths, while the $\mathrm{Y}$ direction is stronger. This is the "thickness" direction of the as-received foam sheet. Samples for the following measurements were cut with longitudinal directions in the $\mathrm{X}$ and $\mathrm{Z}$ directions. 


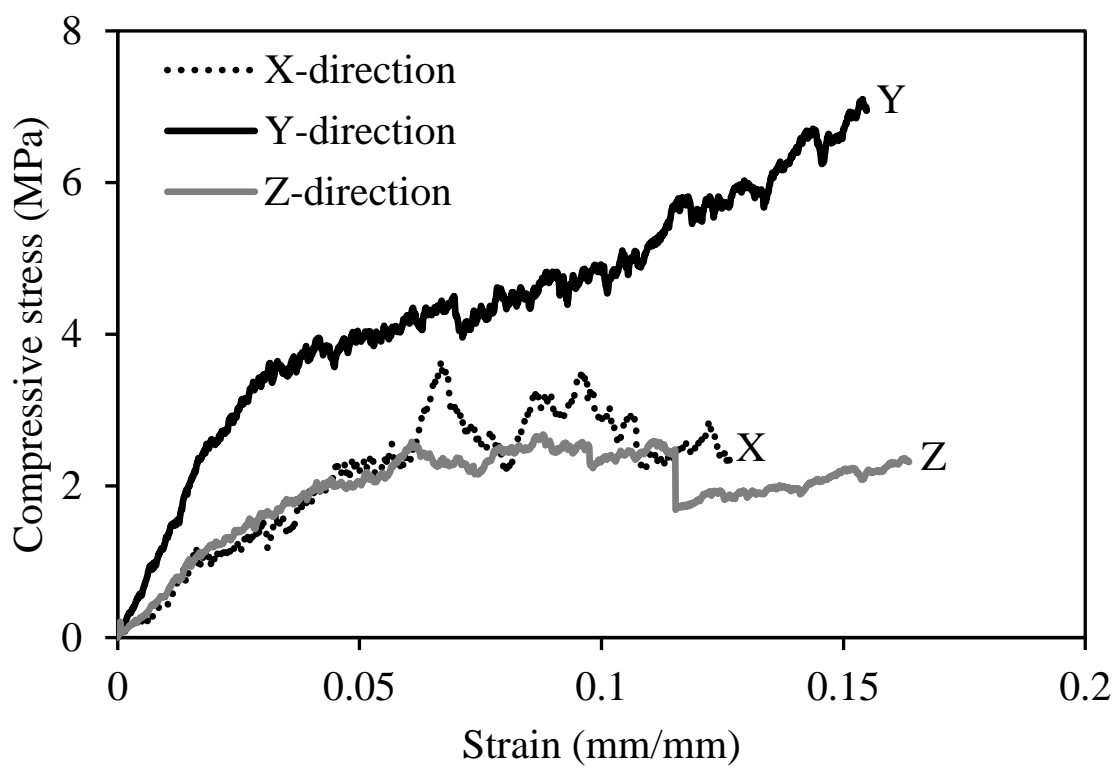

Figure 13. Typical stress-strain curve of the $\mathrm{SiC}$ ceramic foam showing the three strength directions, $\mathrm{X}, \mathrm{Y}$ and $\mathrm{Z}$.

The compressive stress-strain behaviors of the $\mathrm{A} 356 / \mathrm{SiC}$ foam composite with and without nickel are given in Figure 14 in which the axial strain was measured by strain gauge.

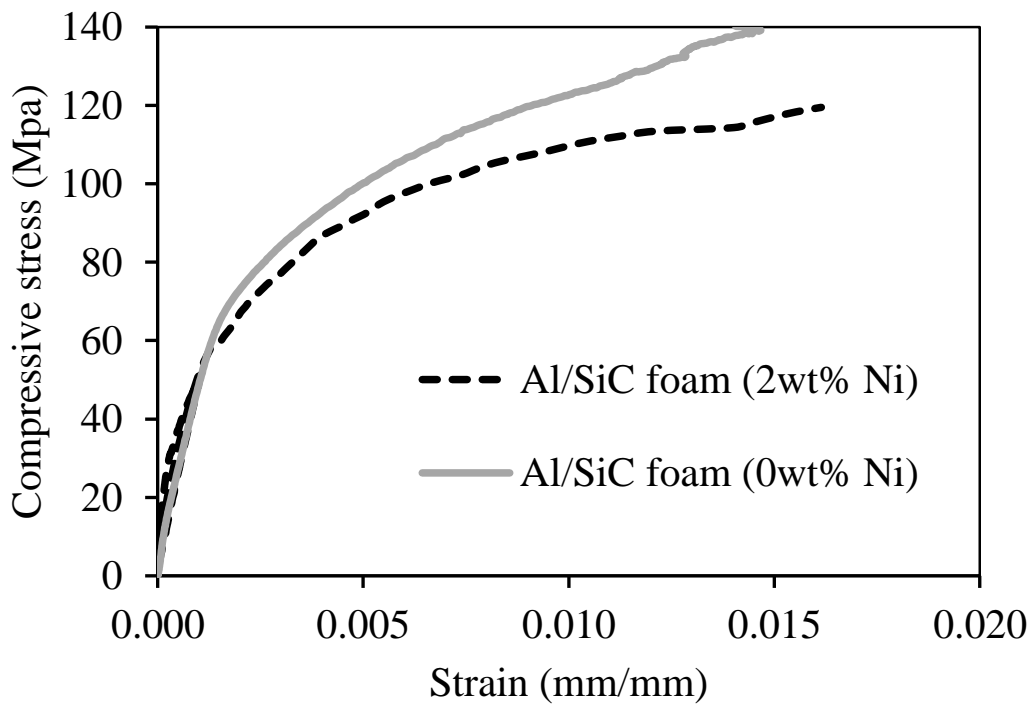

Figure 14. Compressive stress-strain results for the $\mathrm{A} 356 / \mathrm{SiC}$ foam composite. 
The $0 \mathrm{wt} \% \mathrm{Ni}$ and $2 \mathrm{wt} \% \mathrm{Ni} \mathrm{A} 356 / \mathrm{SiC}$ foam composites have average Young's moduli of $76.36 \pm 1.51 \mathrm{GPa}$ and $80.60 \pm 2.55 \mathrm{GPa}$, respectively. Addition of nickel increases the average composite stiffness by $5.5 \%$. This new composite (without nickel) has a $9.1 \%$ higher stiffness than the A356 aluminum alloy matrix material (72.4 GPa observed by Premhmar, (1997)) indicating the $\mathrm{SiC}$ network is making the composite stiffer. Although the composite has low reinforcement concentration (approximately $12 \mathrm{vol} \%$ ), an increased stiffening does occur. In the literature, the Young's modulus of typical $\mathrm{Al} / \mathrm{SiC}$ particulate MMCs employed for packaging materials ranges from $167 \mathrm{GPa}$ to $192 \mathrm{GPa}$ for $55 \mathrm{vol} \%$ and $63 \mathrm{vol} \% \mathrm{SiC}$, respectively (Rao et al., 2006). The SiC struts being stiffer than the aluminum alloy are assumed to hold the load until they start to break under the applied load at approximately 50-70 MPa as shown in Figure 14. The curves follow a pattern having an initial linear elastic deformation where strut wall bending occurs. As the stress level increases, the brittle struts reach their peak strength value and gradually buckle reaching a short elastic-plastic plateau. Upon further loading, the matrix begins to carry the load and plastically deforms in a ductile manner. As the stress increases, the strain increases due to bending, buckling, collapsing and crushing of the struts, thereby densifying the composite. To understand how failure of the struts occurred subsequent to compressive loading, the internal damage was observed using SEM images. A representative microstructure of the composite prior to compression testing is given in Figure 15. A typical sample evaluated at 3.3\% strain was cross-sectioned in the longitudinal direction, parallel to the load direction as shown in Figure 16. The micro-structural damage is dominated by broken, cracked and delaminated SiC struts. 


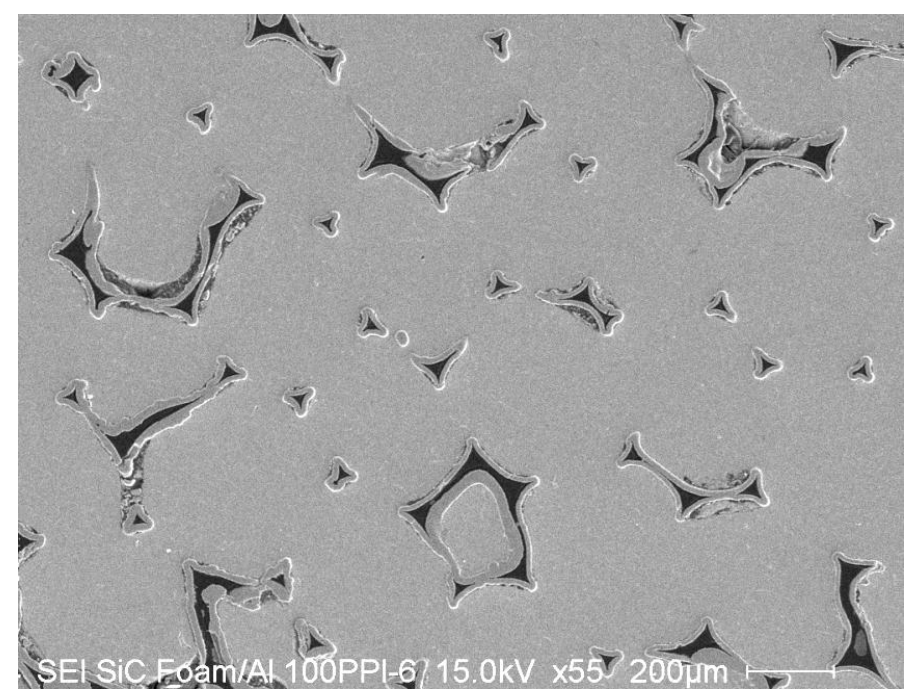

Figure 15. Typical microstructure prior to compression testing.

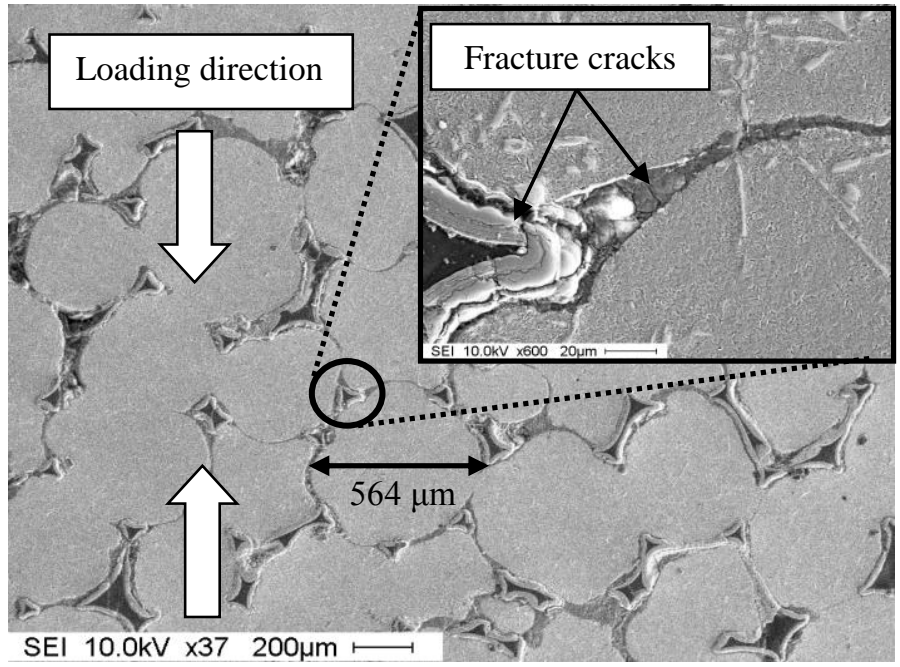

Figure 16. Typical microstructure subsequent to compression testing.

\subsubsection{Flexural Strength Test}

All sample geometries were ground finished to 600 grit silicon carbide paper on four sides to remove any stress concentrations due to machining. Samples with $0 \%$ and $2 \%$ nickel were tested to measure the flexural strength of the composite. The experimental flexural strength results for the $\mathrm{A} 356 / \mathrm{SiC}$ foam composite with varying porosities, along with typical values for $\mathrm{Al} / \mathrm{SiC}$ (70 vol\% reinforcement) are shown in Figure 17. The flexural strength of an A356 aluminum alloy is approximately $375 \mathrm{MPa}$ and $\mathrm{Al} / \mathrm{SiC}$ (70 vol\% $\mathrm{SiC}$ ) MMC is currently employed in electronic 


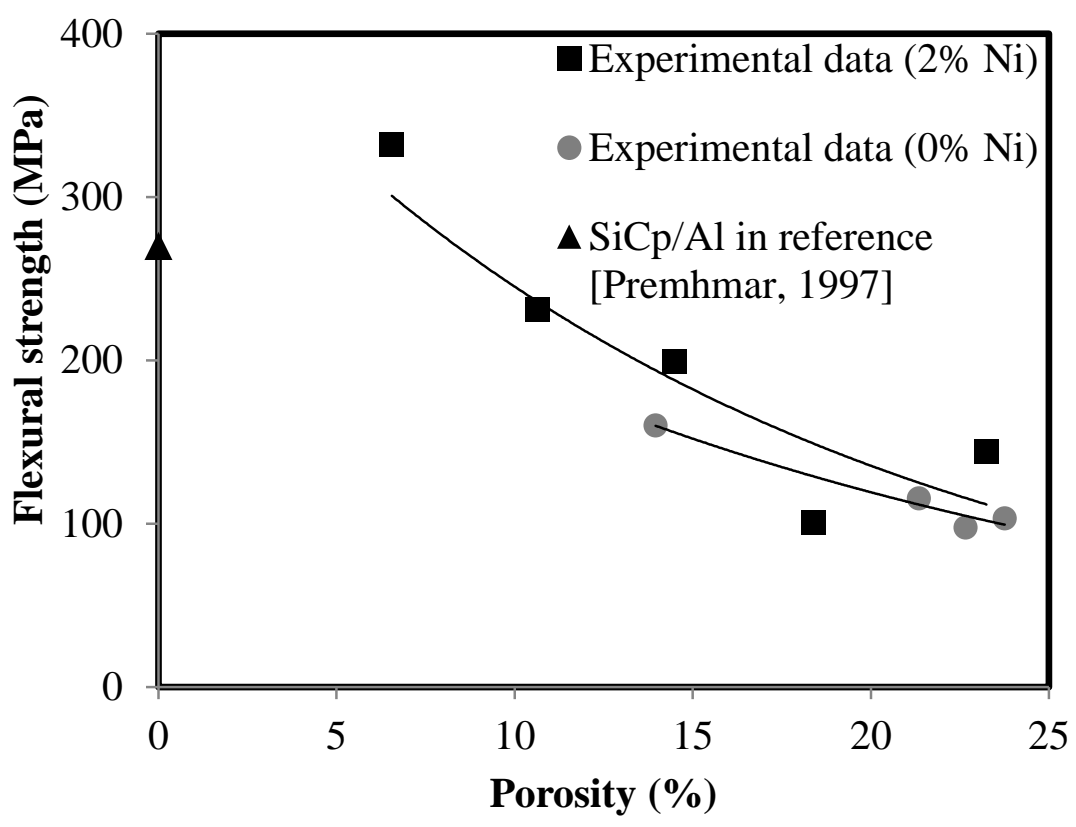

Figure 17. Flexural strength versus porosity for individual tests performed.

packaging base plates with a bend strength of $270 \mathrm{MPa}$ (Premhmar, 1997). Generally, adding 2\% nickel increased the strength of the composite. The highest flexural strength occurs at $332 \mathrm{MPa}$, for a composite with $7 \%$ porosity. Lower strength values are due to porosity. However, with only $12 \% \mathrm{SiC}$ reinforcement and $7 \%$ porosity, this material is comparable to typical $\mathrm{Al} / \mathrm{SiC} \mathrm{MMC}$ with $70 \% \mathrm{SiC}$ particles. If porosity is decreased, the overall flexural strength would increase and be superior to conventional base plates for electronic packaging materials.

\subsubsection{Charpy Test}

The total impact energy for $\mathrm{A} 356 / \mathrm{SiC}$ foam composite specimens ranged from 1.23-1.34 $\mathrm{J}$ for notched and un-notched samples, respectively. These are typical energies for IPCs as reported for an $\mathrm{Al}_{2} \mathrm{O}_{3} / \mathrm{Al}$ composite of $1.3 \mathrm{~J}$ by La Vecchia et al. (2003). Figure 18, shows the impact strength results for notched and un-notched Charpy specimens with $0 \%$ and $2 \%$ nickel. The results are compared against literature data investigated by Jenabali Jaromi et al. (2004) for un- 


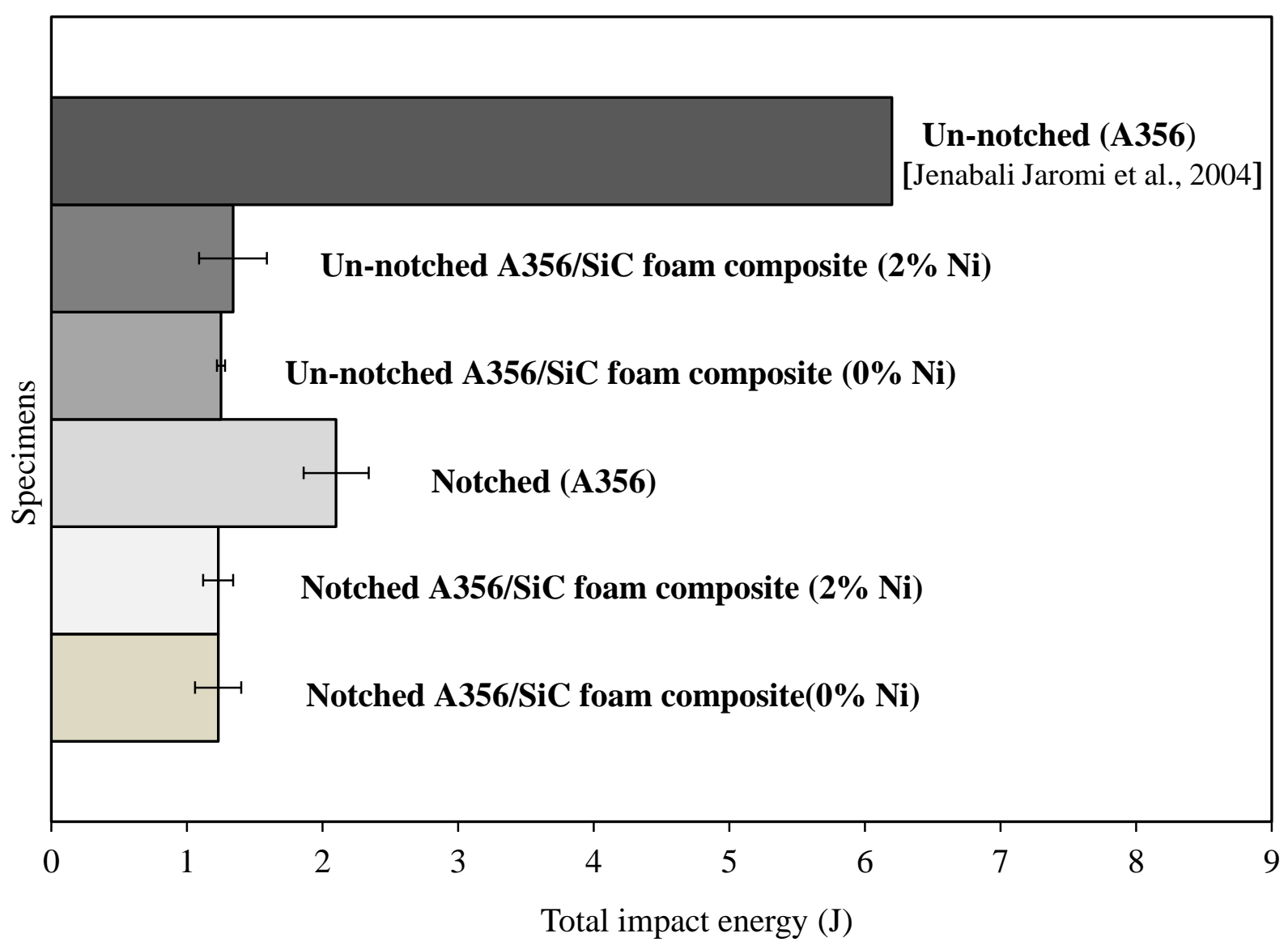

Figure 18. Charpy impact energy for notch and un-notched samples.

notched A356 aluminum alloy. The reduction in toughness from the as-received A356 aluminum alloy is due to the presence of the $\mathrm{SiC}$ strut 3-D network structure, as it acts as stress concentrations making the composite more fracture sensitive than the pure matrix. Both notched A356/SiC foam composites with $0 \%$ and $2 \%$ nickel have the same impact energies of $1.23 \mathrm{~J}$. Likewise, the un-notched $0 \%$ and $2 \%$ nickel samples have similar impact energies. This suggests that adding 2 wt\% of nickel does not significantly affect toughness. Notched and unnotched sample have similar impact energies indicating an absence of notch sensitivity. 


\subsubsection{Flexural and Charpy Fractured Surface}

The A356/SiC foam composite flexural and Charpy notched and un-notched, fracture surfaces show similar fracture. The A356 aluminum-silicon alloy matrix show signs of mixed fracture. Cleavage regions are shown as large flat surface areas and are related to brittle failure while some dimpling also occurs depicted by white regions and are related ductile failure as shown in Figure 19. There is more brittle than ductile fracture which explains the low impact values obtained. A356 alloy with its $7 \mathrm{wt} \%$ silicon content was utilized due to its good flowability characteristics for casting as well as preventing intermetallic aluminum carbide $\left(\mathrm{Al}_{4} \mathrm{C}_{3}\right)$ from forming, however brittle silicon particles in the aluminum matrix tend to deteriorate the ductility of the aluminum.

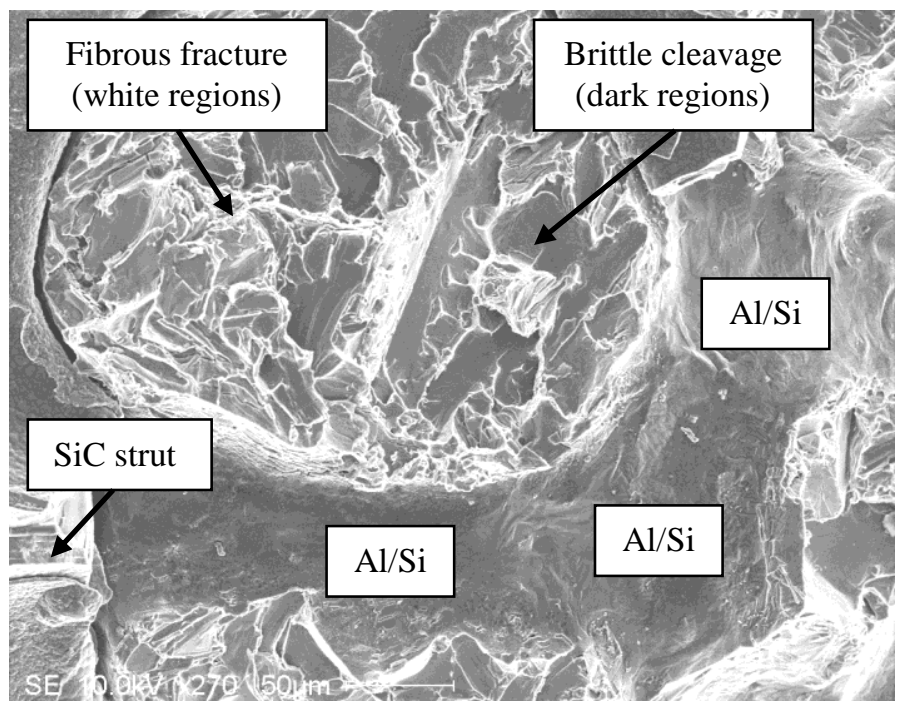

Figure 19. Typical SEM fractured surface of $\mathrm{A} 356 / \mathrm{SiC}$ foam composite.

Three different fractured regions can be observed from the $\mathrm{SiC}$ reinforcement strut of Figure 20. A fracture of the multi-layered strut, de-bonding of a single layer from both the matrix and its reinforcement and a missing layer, presumably attached to the second fractured portion of the flexural test specimen. Areas with missing layers, indicate a strong interface bond between the 
$\mathrm{SiC}$ layer and the matrix but a lower bond strength between the individual $\mathrm{SiC}$ layers. Due to this unique structure, the failure cracks propagate through the brittle ceramic struts and are stopped by the more ductile aluminum phase. Failure occurs by strut cracking, $\mathrm{SiC}$ interlayer de-bonding followed by matrix cleavage and dimpling. It can be concluded that both the matrix and reinforcement are brittle in nature individually and combined together.

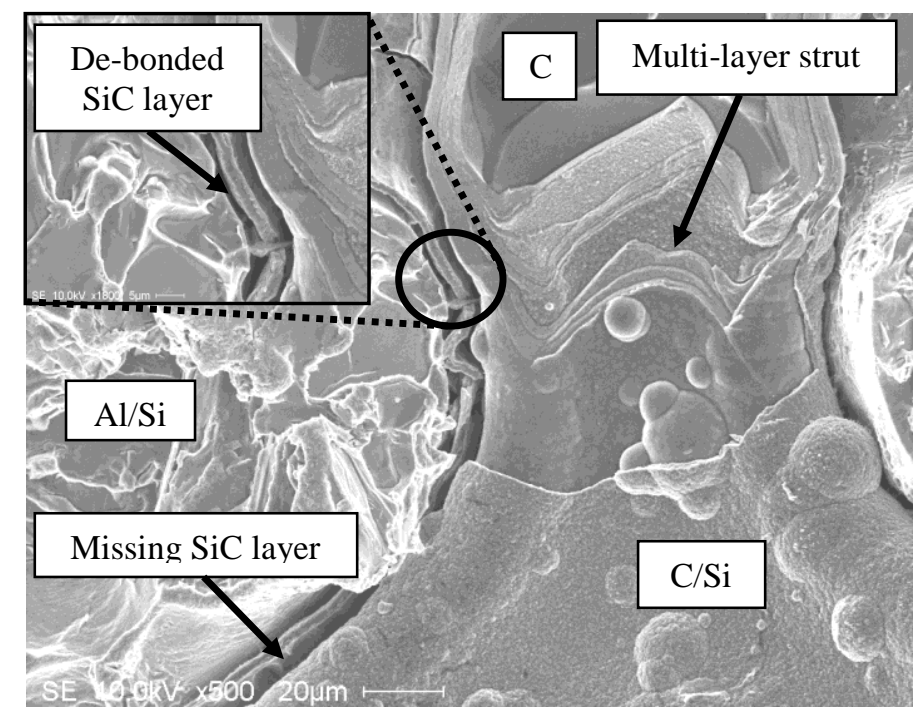

Figure 20. Typical SEM flexural fracture surface of A356/SiC foam composite.

\subsection{Thermal Properties}

The experimental thermal diffusivity results at ambient temperature $\left(25^{\circ} \mathrm{C}\right)$ are $51 \pm 1.82 \mathrm{~mm}^{2} / \mathrm{s}$ and $40 \pm 3.04 \mathrm{~mm}^{2} / \mathrm{s}$ for $0 \mathrm{wt} \%$ and $2 \mathrm{wt} \%$ nickel, respectively for $12 \mathrm{vol} \% \mathrm{SiC}$ network reinforcement and 7\% composite porosity. The thermal diffusivity is calculated using Equation 9, where the density of the composite ( $\rho_{\text {comp }}$ ) was obtained from Archimedes method to be 2.52 $\operatorname{Mgm}^{-3}$ : specific heat capacity $\left(\mathrm{C}_{\mathrm{p}}^{\mathrm{c}}\right)$, and thermal conductivity $\left(\mathrm{k}_{\mathrm{c}}\right)$, are obtained from their respective ROM equations. Equation 9 overestimates the thermal diffusivity of the current material. This can be attributed to the network structure of the foam as opposed to the aligned fibers assumed in the ROM and the influence of the porosity, hence the lower diffusivity value 
compared to the commercial packaging material with $65 \% \mathrm{SiC}$ particulate content $\left(63 \mathrm{~mm}^{2} / \mathrm{s}\right)$ (Rao et al., 2006). The thermal diffusivity of the $\mathrm{Al} / \mathrm{SiC}$ foam composite deteriorates as temperature increases. An increase from $25^{\circ} \mathrm{C}$ to $275^{\circ} \mathrm{C}$, brings about a thermal diffusivity decrease of $12 \%$ for the nickel-free, and $8 \%$ for 2 wt $\%$ nickel, samples. (The addition of 2 wt $\%$ nickel reduces the diffusivity of the composite by approximately $10.5 \%$, at room temperature.) The experimental specific heat capacities $\left(\mathrm{C}_{\mathrm{p}}\right)$ at ambient temperature $\left(25^{\circ} \mathrm{C}\right)$ are $0.79 \pm 0.035$ $\mathrm{J} / \mathrm{g} \cdot \mathrm{K}$ and $0.67 \pm 0.062 \mathrm{~J} / \mathrm{g} \cdot \mathrm{K}$ for $0 \mathrm{wt} \%$ and $2 \mathrm{wt} \%$ nickel, respectively for $12 \mathrm{vol} \% \mathrm{SiC}$ network reinforcement and $7 \%$ composite porosity. The ROM, Equation 10, was employed for determining the $\mathrm{C}_{\mathrm{p}}$ of this composite where superscripts $\mathrm{c}, \mathrm{m}$, and $\mathrm{r}$ refer to the composite, matrix and reinforcement, respectively and $\mathrm{V}$ represents the volume fraction of the phase (Christian and Campbell, 1972). This equation is accurate for continuous fibers in transversely isotropic composites where the matrix is considered to be isotropic and the reinforcement is anisotropic.

$\mathrm{C}_{\mathrm{p}}^{\mathrm{c}}=\left(\mathrm{V}_{\mathrm{r}} \mathrm{C}_{\mathrm{p}}^{\mathrm{r}}+\mathrm{V}_{\mathrm{m}} \mathrm{C}_{\mathrm{p}}^{\mathrm{m}}\right)$

To remove heat quickly, the base plate material will require a low specific heat capacity. Typical $\mathrm{Al} / \mathrm{SiC}$ packaging materials with $65 \% \mathrm{SiC}$ particle content have a heat capacity of 0.78 $\mathrm{J} / \mathrm{g} \cdot \mathrm{K}$ (Rao et al., 2006) at ambient temperature, while the present composite, with no nickel has a similar heat capacity $(0.79 \mathrm{~J} / \mathrm{g} \cdot \mathrm{K})$, but with only $12 \mathrm{vol} \% \mathrm{SiC}$. The difference between the experimental and theoretical ROM specific heat capacity value is $10 \%$ for the composite with $0 \%$ nickel. This is due to the porosity present in the composite and the foam strut network. The calculated thermal conductivity results of the $\mathrm{A} 356 / \mathrm{SiC}$ foam composite at ambient temperature $\left(25^{\circ} \mathrm{C}\right)$ are $97 \mathrm{~W} / \mathrm{m} \cdot \mathrm{K}$ and $87 \mathrm{~W} / \mathrm{m} \cdot \mathrm{K}$ for $0 \mathrm{wt} \%$ and $2 \mathrm{wt} \%$ nickel, respectively, for $12 \mathrm{vol} \%$ $\mathrm{SiC}$ network reinforcement and 7\% composite porosity. 
The heat flow through the composite, parallel or along the fiber direction can be predicted by the parallel ROM model, the series ROM (Thornburgh and Pears, 1965) or the Effective Medium Theory (EMT) model (Wang et al., 2006) which assumes a heterogeneous material, where the two phases are distributed randomly. However as the thermal conductivities of the two pure phases are relatively close $(120$ and $150 \mathrm{~W} / \mathrm{m} \cdot \mathrm{K}$ for $\mathrm{SiC}$ and aluminum, respectively) the calculated conductivities as a function of volume fraction reinforcement from all three models are very close. The experimental thermal conductivity values are lower than predicted due to porosity in the $\mathrm{Al} / \mathrm{SiC}$ foam composite. The thermal conductivity increases for the $\mathrm{Al} / \mathrm{SiC}$ composite, as the temperature increases, following the trend of the aluminum alloy, the one with the highest phase volume fraction. For $0 \mathrm{wt} \% \mathrm{Ni}$, the increase from $25^{\circ} \mathrm{C}$ to $275^{\circ} \mathrm{C}$ is approximately $24 \%$ while for $2 \mathrm{wt} \% \mathrm{Ni}$, the increase is $16 \%$. By adding $2 \mathrm{wt} \% \mathrm{Ni}$, the thermal conductivity drops by $10 \%$ at $25^{\circ} \mathrm{C}$ due to the lower thermal conductivity of nickel (90.9 $\mathrm{W} / \mathrm{m} \cdot \mathrm{K})$.

The experimental linear coefficient of thermal expansion (CTE) results at ambient temperature $\left(25^{\circ} \mathrm{C}\right)$ are $9.6 \mathrm{ppm} /{ }^{\circ} \mathrm{C}$ and $9.0 \mathrm{ppm} /{ }^{\circ} \mathrm{C}$ for $0 \mathrm{wt} \%$ and $2 \mathrm{wt} \%$ nickel, respectively for $12 \mathrm{vol} \% \mathrm{SiC}$ network reinforcement. The CTE is theoretically predicted using two models frequently employed for ceramic metal composites to estimate the upper and lower limit approximations; the ROM and Turner models (Hsieh and Tuan, 2007) The ROM estimates the CTE in the transverse direction of a two-phase composite material, given by Equation 11. This model assumes no thermal interaction (the phases are not constrained by each another) and similar bulk moduli. Each phase expands or contracts at different rates. During expansion, the model assumes equal stresses (or no stress transfer between the matrix and reinforcement) throughout the two phases in the composite (iso-stress). 
$\alpha_{\mathrm{c}}=\alpha_{\mathrm{r}} \mathrm{V}_{\mathrm{r}}+\alpha_{\mathrm{m}} \mathrm{V}_{\mathrm{m}}$

Where $\alpha_{c}, \alpha_{\mathrm{r}}$ and $\alpha_{\mathrm{m}}$ are the CTE of the composite, fiber/reinforcement and matrix, respectively. The Turner equation estimates a lower limit of the linear CTE in the longitudinal direction of a two-phase composite material, given by Equation 12, where $\mathrm{K}$ is the bulk modulus of each phase. This model assumes thermal interaction (the phases are constrained by each other) and dissimilar modulus values between the matrix and the reinforcement. Each constituent dimension is assumed to change, expand or contract at the same rate as the overall composite. The model assumes equal strains throughout the two phases in the composite (iso-strain). When $K_{m}=K_{r}$, the Turner model is equal to the ROM model.

$\alpha_{c}=\left(\alpha_{m} V_{m} K_{m}+\alpha_{r} V_{r} K_{r}\right) /\left(V_{m} K_{m}+V_{r} K_{r}\right)$

Figure 21 depicts the experimental and theoretical model predictions of the CTE for the A356/SiC foam composite.

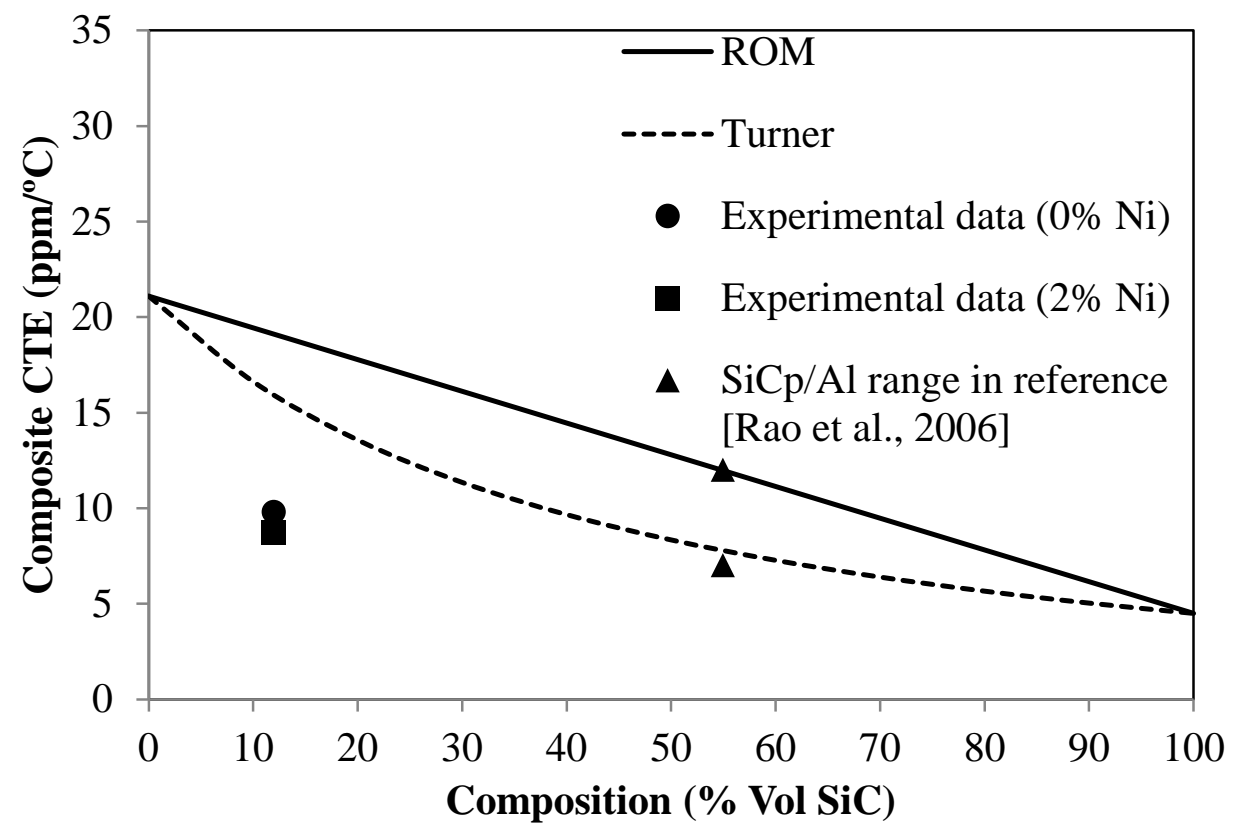

Figure 21. Comparison between experimental and theoretical CTE as a function of volume fraction reinforcement. 
Typical $\mathrm{Al} / \mathrm{SiC}$ particle electronic packaging materials ranges between 7 to $12 \mathrm{ppm} /{ }^{\circ} \mathrm{C}$ (Rao et al., 2006) for $55 \mathrm{vol} \% \mathrm{SiC}$ at ambient temperatures. By incorporating $12 \mathrm{vol} \% \mathrm{SiC}$ foam network structure into the aluminum, the CTE is $9.7 \mathrm{ppm} /{ }^{\circ} \mathrm{C}$ whereas, it requires $55 \mathrm{vol} \%$ of dispersed $\mathrm{SiC}$ particles to attain a similar value. The interconnected network struts of the foam place a restriction on the expansion of the matrix, as opposed to dispersed $\mathrm{SiC}$ particles which can move independently from each other upon expansion of the matrix.

As expected, both CTE models show a decrease in CTE as the amount of $\mathrm{SiC}$ is increased, as a consequence of the lower CTE of the SiC. The present results are approximately $30 \%$ to $50 \%$ lower than the theoretical models due to the inadequacies of the models to represent the behaviour of the two interconnected phases. The ROM assumes the metal and ceramic phases are independent of one another and are able to expand at their respective rates, without any constraint, while in the Turner model, the overall expansion of the composite is constrained by the phase with the lowest CTE. The experimental CTE may also be low due to the porosity incurred from solidification shrinkage between the matrix and reinforcement struts. Upon heating, the matrix may plastically deform, expanding into the porous areas thus lowering the overall CTE of the composite.

The CTE as a function of temperature for this network composite initially behaves differently than particulate composites as shown in Figure 22. Data for Duralcan SiC/A359 aluminum alloy composites with $10 \%$ and $40 \% \mathrm{SiC}$ particulate reinforcement as reported by Lemieux et al. (1998) are plotted for comparison. At low temperatures, below $50^{\circ} \mathrm{C}$, the initial CTE curves of the $\mathrm{Al} / \mathrm{SiC}$ foam composite exhibits a very different behavior to Duralcan A359/SiC with 10-40 vol\% $\mathrm{SiC}$ particles (Lemieux et al., 1998). In this A356/SiC foam composite, the CTE initially rises sharply, then tapers to gradually increase with temperature. 


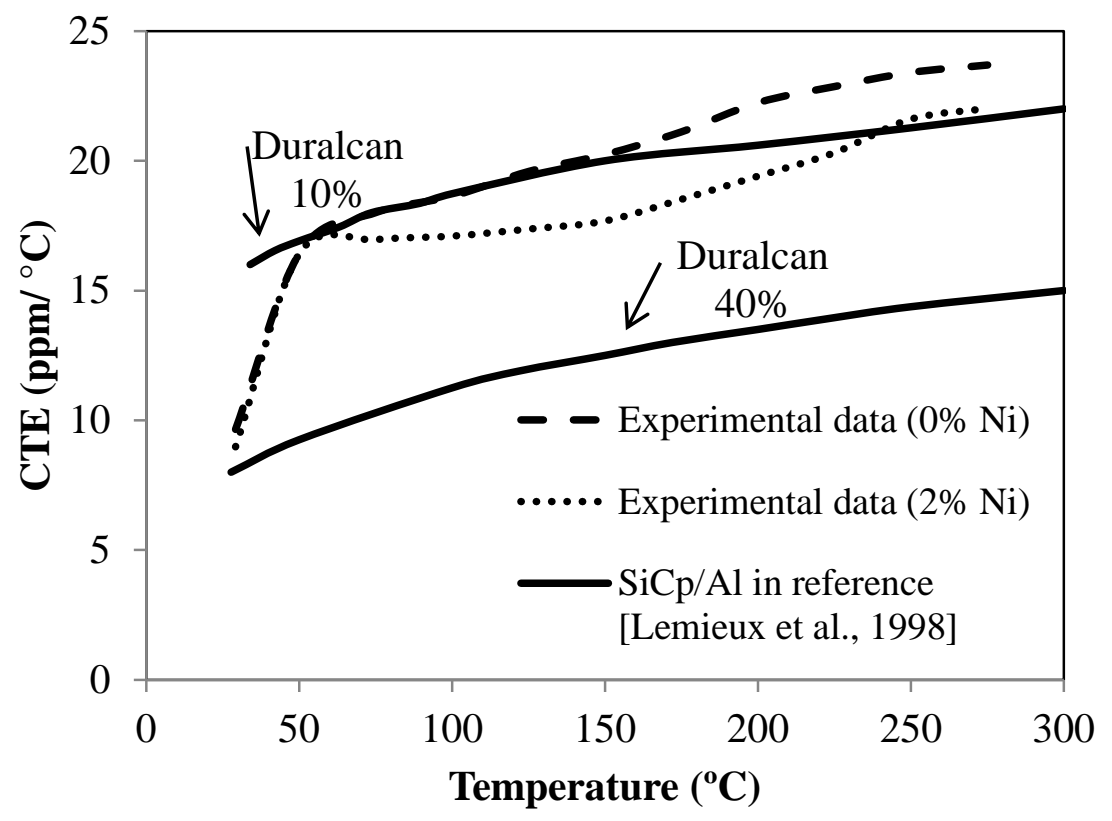

Figure 22. Comparison between experimental and literature CTE as a function temperature.

Once the rapid change in CTE has occurred, the behavior is similar to the particulate reinforced $\mathrm{Al} / \mathrm{SiC} \mathrm{MMCs}$. The reason for this sharp initial increase in CTE of the $\mathrm{Al} / \mathrm{SiC}$ foam composite is due to MMC misfit strains at the $\mathrm{Al} / \mathrm{SiC}$ interface, which have been well studied by Vogelsand et al. (1986). The strains arise due to the large CTE variation between the aluminum and $\mathrm{SiC}(5: 1)$. After vacuum infiltration, as the composite aluminum and $\mathrm{SiC}$ cool, they want to contract at different rates. These thermal stresses generate dislocations at the $\mathrm{Al} / \mathrm{SiC}$ interface. Therefore, during initial heating of the $\mathrm{CTE}$ test, below $50^{\circ} \mathrm{C}$, a majority of the dislocations (or residual stresses) are annihilated/removed, allowing the CTE rate to increase rapidly. As the temperature gets closer to the melting point of aluminum $\left(660^{\circ} \mathrm{C}\right)$, or greater than $300^{\circ} \mathrm{C}$, the composite $\mathrm{CTE}$ gets closer to that of the CTE of the aluminum. This phenomenon suggests that the dislocations from the differential thermal stresses have been removed and thus allows the atoms to move more freely. As shown in Figure 22, both Duralcan composites with $10 \%$ and $40 \% \mathrm{SiC}$ 
reinforcement do not show such a severe change in CTE initially as the Al/SiC foam composite of this research. The CTE slope in the $\mathrm{Al} / \mathrm{SiC}$ from $25^{\circ} \mathrm{C}$ to $75^{\circ} \mathrm{C}$ is more pronounced in the rigid $\mathrm{SiC}$ network structure than the $\mathrm{SiC}$ particles. This can be explained by the network structure having more surface area, therefore is able to generate much more misfit strains at the $\mathrm{Al} / \mathrm{SiC}$ interface.

\subsection{Theoretical Modeling}

\subsubsection{Modeling the Modulus of MMCs}

The Rule of Mixtures (ROM) upper (Voigt, 1889) and lower (Reuss, 1929) bounds are used to predict the axial and transverse Young's modulus of a two phase composite material arranged as two slabs side by side. These two slab models (iso-stress and iso-strain) assume that both phases have the same Poisson's ratio and deform elastically, and both perfectly bonded alternating phases are aligned parallel and perpendicular to the axial load direction, respectively. A tighter envelope is provided by Hashin and Shtrikman (Hashin and Shtrikman, 1963) upper \& lower bounds (HS bounds) which estimate the upper and lower limits for the elastic Young's modulus of composite based on energy methods for a randomly distributed reinforcement phase, surrounded by a continuous matrix phase.

The experimental results for the $\mathrm{Al} / \mathrm{SiC}$ foam $(0 \% \mathrm{Ni})$ fall outside the predicted $\mathrm{ROM}$ and HS bounds due to two factors. The 3-D, interpenetrating composite structure of the Al-SiC foam cannot be approximated accurately by either of these model structures and the experimental material also includes dispersed porosity.

Cohen and Ishai (1967) developed a cubic three-phase model for predicting the composite Young's modulus with porosity was used to compare with the experimental values. The lower bound modulus for the three phase composite is obtained from Equation 13 where $\mathrm{E}_{\mathrm{m}}$ 
is the modulus of the matrix with no porosity, $\mathrm{V}_{\mathrm{f}}$ is the volume fraction of the reinforcement, $\mathrm{m}$, is the reinforcement to matrix modulus ratio, and $\mathrm{m}^{*}$ is the ratio of the reinforcement modulus to the matrix modulus with porosity $\left(\mathrm{E}_{\mathrm{f}} / \mathrm{E}_{\mathrm{cp}}\right)$ given by Equation 14 .

$$
\begin{aligned}
& E_{c 3}=E_{m}\left(1-V_{v}^{2 / 3}\right)\left[1+\frac{V_{f}}{\frac{m *}{m *-1}-\left(V_{f}\right)^{1 / 3}}\right] \\
& E_{c p}=E_{m}\left(1-V_{v}{ }^{2 / 3}\right)
\end{aligned}
$$

For the same cubic configuration as above, the three-phase composite modulus $\left(\mathrm{E}_{\mathrm{c} 3}\right)$ for the upper limit is found from Equations 15 and 16.

$$
\begin{aligned}
& E_{c 3}=E_{m}\left[\frac{1-V_{v}^{2 / 3}}{\left.1-V_{v}^{2 / 3}-V_{v}\right)}\right]\left[\frac{1+\left(m^{*}-1\right)\left(V_{f}\right)^{2 / 3}}{1+\left(m^{*}-1\right)\left(V_{f}^{2 / 3}-V_{f}\right)}\right] \\
& E_{c p}=E_{m}\left[\frac{1-V_{v}^{2 / 3}}{\left.1-V_{v}{ }^{2 / 3}-V_{v}\right)}\right]
\end{aligned}
$$

For the 12 vol\% $\mathrm{SiC}(\mathrm{E}=243 \mathrm{GPa})$ foam and $\mathrm{A} 356$ aluminum alloy $(\mathrm{E}=72.4 \mathrm{GPa})$ composite with $8.5 \%$ porosity, the Cohen and Ishai cubic model predicts upper and lower moduli of $82 \mathrm{GPa}$ and $68 \mathrm{GPa}$, repectively. The experimental A356/SiC (0wt\% Ni) composite has a modulus of 76.4 GPa. The experimental results fall within the cubic upper and lower bounds suggesting that the model is applicable for this porosity level.

\section{Conclusion}

A simple and inexpensive manufacturing technique was developed for producing a novel IPC material. It consists of vacuum infiltrating an A356 aluminum alloy into a SiC ceramic foam network. The resulting microstructure morphology, composition, density, porosity and nanoindentation behavior were determined. This composite yields a significant reduction in density due to the low $\mathrm{SiC}$ volume fraction reinforcement used in the form of foam, rather than 
particulates. The lowest total porosity obtained using the vacuum infiltration apparatus was $7 \%$. From the micrographs, it appears the porosity is due to inherent aluminum solidification shrinkage at the $\mathrm{SiC} / \mathrm{Al}$ interface and some microporosity, however, the majority of the composite is well infiltrated. XRD did not reveal any contamination in the melt after ten infiltrations from either the quartz tube or the high temperature cement, and did not detect intermetallics. Compositional analysis revealed the nickel coating in the foam did not dissolve in the aluminum alloy matrix nor segregated around the grain boundaries, but remained on the surface of the $\mathrm{SiC}$ foam after aluminum infiltration.

The A356/SiC foam network composite manufactured by a low vacuum infiltration manufacturing process produced interesting mechanical and thermal properties. An outstanding advantage of this composite is that with only $12 \%$ volume fraction $\mathrm{SiC}$ reinforcement content, comparable mechanical and thermal properties were obtained to composites with $\mathrm{Al} / \mathrm{SiC}$ 50-70 vol\% particulates. The solid network structure was shown to contribute more to the properties than if the reinforcement is a distribution of isolated particles. This research has provided new information about the microstructure, mechanical and thermal behavior of an $\mathrm{A} 356 / \mathrm{SiC}$ foam composite. The results indicate promising properties for use in the electronic packaging industry, specifically in light-weight applications for aerospace and space applications. 


\section{References}

Ahson, J.P., Gruzleski, J.E., 1999. The quantitative discrimination between shrinkage and gas microporosity in cast aluminum alloys using spatial data analysis. Mater. Charact. 43, 319-335.

ASTM C 20-00, 2000. Standard test methods for apparent porosity, water absorption, apparent specific gravity, and bulk density of burned refractory brick and shapes by boiling water. ASTM International, West Conshohocken, PA, www.astm.org.

ASTM C 1161-02, 2002. Standard test method for flexural strength of advanced ceramics at ambient temperature. ASTM International, West Conshohocken, PA, www.astm.org.

ASTM E 23-02, 2002. Standard test method for notched bar impact testing of metallic materials. ASTM International, West Conshohocken, PA, www.astm.org.

Bindumadhavan, P.N., Wah, H.K., Prabhakar, O., 2002. Assessment of particle-matrix debonding in particulate metal matrix composites using ultrasonic velocity measurements. Mater. Sci. Eng. A323, 42-51.

Chen, L.G., Shue, K.H., Chang, S.Y., Lin, S.J., 2002. Squeeze casting of $\mathrm{SiC}_{\mathrm{P}} / \mathrm{Al}$-alloy composites with various contents of reinforcements. J. Mater. Res. 17, 376-385.

Christian, J.L., Campbell, M.D., 1972. In: Timmerhaus, K (ed.), Proceedings of the 1972 Cryogenic Engineering Conference, Advances in Cryogenic Engineering, Boulder Colorado, USA, pp. 175-183.

Chung, W.S., Lin, S.J., 1996. Ni-coated $\mathrm{SiC}_{\mathrm{P}}$ reinforced aluminum composites processed by vacuum infiltration. Mater. Res. Bull. 31, 1437-1447.

Cohen, L.J., Ishai, O., 1967. The elastic properties of three-phase composites. J. Compos. Mater. 1, 390-403.

Cowlard, F.C., Lewis J.C., 1967. Vitreous carbon-a new form of carbon. J. Mater. Sci. 2, 507-512.

Hashin, Z., Shtrikman, S., 1963. A variational approach to the theory of elastic behavior of multiphase materials. J. Mech. Phys. Solids. 11, 127-140.

Hatch, J.E., 1984. Aluminum: Properties and Physical Metallurgy. Metals Park, Ohio, p. 235.

Hsieh, C.L., Tuan, W.H., 2007. Thermal expansion behavior of a model ceramic-metal composite. Mater. Sci. Eng., A. 460-461, 453-458. 
Jenabali Jaromi, S.A., Dehghan, A., Malekjani, S., 2004. Effects of optimum amount of $\mathrm{Sr}$ and $\mathrm{Sb}$ modifiers on tensile, impact and fatigue properties of A356 aluminum alloy. Iran. J. Sci. \& Technol. Trans. B. 28, 225-232.

Jitendra S.G., Pickering, M.A., Taylor, R.L., Murray, B.W., Lompado, A., 1991. Properties of chemical-vapor-deposition silicon carbide for optics applications in severe environments. Appl. Opt. 30, 3166-3175.

Kaufman, J.G., 2004. Aluminum alloy castings: properties, processes, and applications. ASM, Materials Park, Ohio, pp. 49-54.

La Vecchia, G.M., Badini, C., Puppo, D., D'Errico, F., 2003. Co-continuous $\mathrm{Al} / \mathrm{Al}_{2} \mathrm{O}_{3}$ composite produced by liquid displacement reaction: relationship between microstructure and mechanical behavior. J. Mater. Sci. 38, 3567-3577.

Lemieux, S., Elom, S., Nemes, R.J., Skibo, M.D., 1998. Thermal expansion of isotropic Duralcan metal-matrix composites. J. Mater. Sci. 33, 4381-4387.

Leon, C.A., Drew, R.A.L., 2000. Preparation of nickel-coated powders as precursors to reinforce MMCs. J. Mater. Sci. 35, 4763-4768.

Li, K., Gao, X.L., Roy, A.K., 2003. Micromechanics model for the three-dimensional open-cell foams using a tetrakaidecahedral unit cell and Castigliano's second theorem. Compos. Sci. Technol. 63, 1769-1781.

Occhionero, M.A., Hay, R.A., Adams, R.W., Fennessy, K.P., 1999. Aluminum silicon carbide (AlSiC) for cost-effective thermal management and functional microelectronics packaging design solutions. In Proceedings of the $12^{\text {th }}$ European Microelectronics and Packaging Conference, Harrogate, U.K., S10-04.

Paccaud, O., Derre, A., 1995. Silicon carbide coating for carbon materials produced by a pack-cementation process. Journal de Physique IV, Colloque C5, supplement au Journal de Physique II, Volume 5, 135-142.

Prangnell, P.B., Downes T., Withers, P.J., Stobbs, W.M., 1994. The deformation of discontinuously reinforced MMCs-II, the elastic response. Acta Metall. et Mater. 42, 3437-3442.

Premhmar, M.K., 1997. Al/SiC for Power Electronics Packaging. In: Proceedings of the 3rd International Symposium on Advanced Packaging Materials, Braselton, Georgia, USA, pp. 162-165.

Quéré, D., 2002. Rough ideas on wetting. Physica A. 313, 32-46. 
Rao, B.S., Hemambar, C., Pathak, A.V., Patel, K.J., Rödel, J., Jayaram, V., 2006. Al/SiC carriers for microwave integrated circuits by a new technique of pressureless infiltration. IEEE Trans. Electron. Packag. Manuf. 29, 58-63.

Reuss, A., 1929. Berechnung der fließgrenze on mischkristallen auf grund der plastizitätbedindingungen für einkristall. J. Appl. Math. Mech. 9, 49-58.

Thornburgh, J.D., Pears, C.D., 1965. Prediction of the thermal conductivity of filled and reinforced plastics. In: ASME Heat Transfer Division, Winter Annual Meeting, 65WA/HT-4.

Vogelsang, M., Arsenault, R.J., Fisher, R.M., 1986. An in-situ HVEM study of dislocation generation at $\mathrm{Al} / \mathrm{SiC}$ interfaces in metal matrix composites. Metall. Trans. A. $17,379-389$.

Voigt, W., 1889. Ueber die beziehung zwischen den beiden elasticitätsconstanten isotroper körper. Ann. Phys. 38, 573-585.

Wang, J., Carson, J.K., North, M.F., Cleland, D.J., 2006. A new approach to modeling the effective thermal conductivity of heterogeneous materials. Int. J. Heat Mass Transfer. 49, 3075-3083.

White, D., Keck, S., Smith, I., Silzars, A., 1990. New ground in hybrid packaging. Hybrid Circuit Technol. 12 (1), 14-19.

Xian-qing, X., Tong-xiang, F., Di, Z., Ren-jie, W., 2002. Increasing the mechanical properties of high damping woodceramics by infiltration with a magnesium alloy. Compos. Sci. Technol. 62, 1341-1346.

Yang, X.F., Xi, X.M., 1995. SiC-Al-Si composites by rapid pressureless infiltration in air. J. Mater. Res. 10, 2415-2417.

Zhao, L.Z., Zhao, M.J., Cao, X.M., Tian, C., Hu, W.P., Zhang, J.S., 2007. Thermal expansion of a novel hybrid $\mathrm{SiC}$ foam-SiC particles-Al composites. Compos. Sci. Technol. 67, 3404-3408. 